UC-528

Issued: November 1996

General-Purpose Heat Source: Research and Development Program, Radioisotope Thermoelectric Generator/Thin Fragment Impact Test

M. A. H. Reimus

J. E. Hinckley

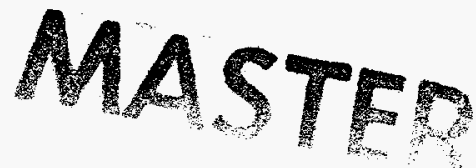




\title{
GENERAL-PURPOSE HEAT SOURCE: \\ RESEARCH AND DEVELOPMENT PROGRAM, RADIOISOTOPE THERMOELECTRIC GENERATOR/THIN FRAGMENT IMPACT TEST
}

\author{
by
}

\author{
M. A. H. Reimus and J. E. Hinckley
}

\begin{abstract}
The general-purpose heat source provides power for space missions by transmitting the heat of ${ }^{238} \mathrm{Pu}$ decay to an array of thermoelectric elements in a radioisotope thermoelectric generator (RTG). Because the potential for a launch abort or return from orbit exists for any space mission, the heat source response to credible accident scenarios is being evaluated. This test was designed to provide information on the response of a loaded RTG to impact by a fragment similar to the type of fragment produced by breakup of the spacecraft propulsion module system. The results of this test indicated that impact by a thin aluminum fragment traveling at $306 \mathrm{~m} / \mathrm{s}$ may result in significant damage to the converter housing, failure of one fueled clad, and release of a small quantity of fuel.
\end{abstract}

\section{INTRODUCTION}

The general-purpose heat source (GPHS) is a modular component of the radioisotope thermoelectric generators (RTGs) that will provide power for the National Aeronautics and Space Administration's Cassini mission to Saturn. An RTG generates electric power by using the heat of ${ }^{238} \mathrm{Pu}$ decay to create a temperature differential across a thermoelectric array. Each RTG is loaded with 18 GPHS modules, and each GPHS module (Figure 1) contains four ${ }^{238} \mathrm{PuO}_{2}$ fuel pellets that provide a total thermal output of about $250 \mathrm{~W}$. Each fuel pellet is encapsulated in a vented DOP-26 iridium alloy shell. Two iridium capsules are held in a Fineweave-Pierced Fabric*(FWPF) graphite impact shell (GIS), and two GISs are contained within an FWPF aeroshell.

*Fineweave-Pierced Fabric, a 3-D carbon/carbon composite, is a product of AVCO Systems Division, 201 Lowell St., Wilmington, MA 01887. 


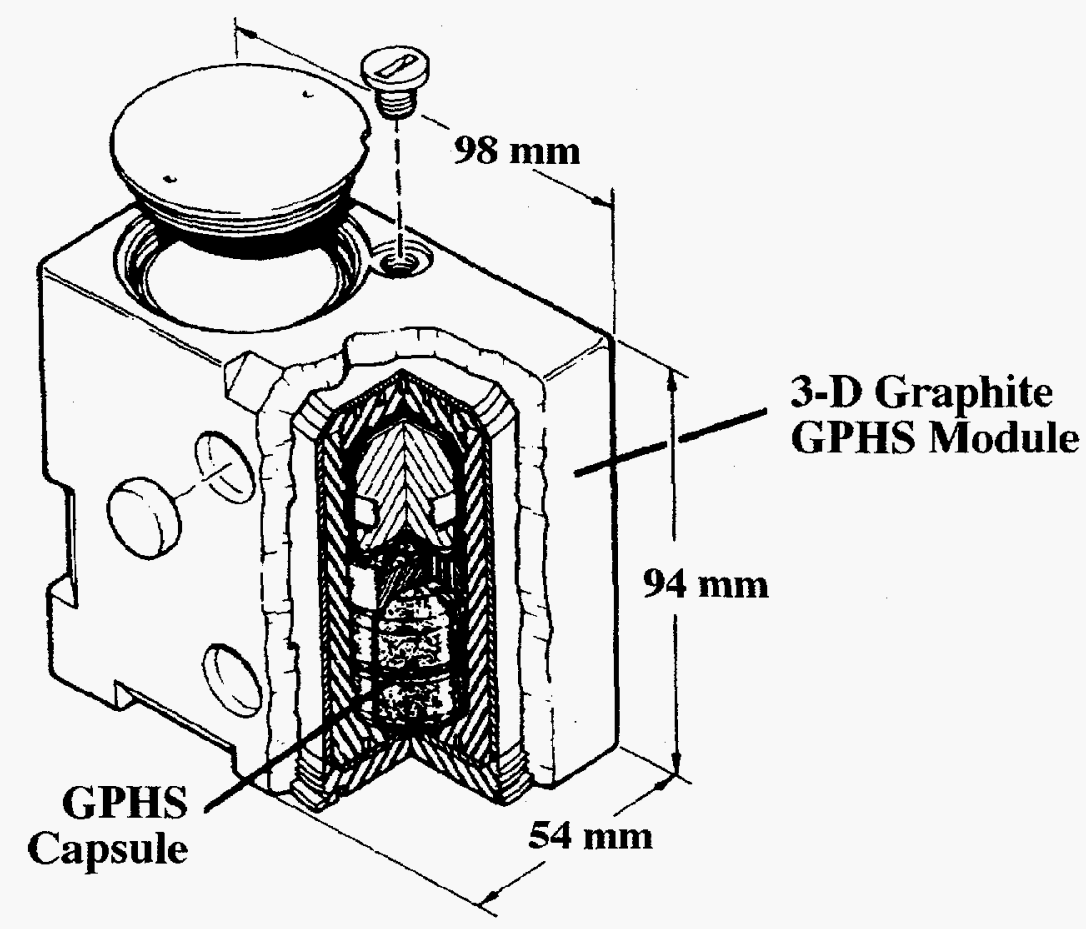

Figure 1. GPHS module.

Because the potential for a launch abort or return from orbit exists for any space mission, the GPHS response to postulated accident scenarios is being evaluated. ${ }^{1}$ Previous testing conducted in support of the Galileo and Ulysses missions documented the response of the GPHS to a variety of fragment-impact, aging, atmospheric reentry, and Earth-impact conditions. ${ }^{2-9}$ Tests that required field testing of heat source and RTG components were performed using GPHS capsules fueled with ${ }^{238} \mathrm{UO}_{2}$ $\left({ }^{235} \mathrm{U}\right.$ depleted) ${ }^{10-14}$ Field testing included solid-propellent fire, explosive overpressure, large fragment interaction, etc.

This report describes test RTG-3. This test, an edge-on fragment-impact test, was third in a series of RTG impact tests. The first two tests, RTG-1 and RTG-2, were designed to provide information on the response of a loaded RTG to end-on impact against a concrete target. ${ }^{15}$ The RTG impact tests were designed to evaluate the response of GPHSs, GPHS modules, and loaded RTGs to conditions that might be experienced as a result of potential on- and near-pad accidents involving failures of the Cassini spacecraft and/or launch vehicle. Specifically, the edge-on fragment-impact test was designed to provide information on the response of a loaded RTG to impact by the type of fragment that might be generated by breakup of the spacecraft propulsion module system (PMS). This test series utilized GPHS capsules fueled with ${ }^{238} \mathrm{UO}_{2}$. 


\section{BACKGROUND}

\section{A. Fabrication of Urania Pellets}

The urania pellets used in this study were fabricated from urania powder produced by Oak Ridge National Laboratory (urania lot NF-30-4225). All of the pellets used were fabricated by cold pressing, followed by sintering. The fabrication technique is described in detail in the following sections.

The urania powder was mixed with a solution of cetyl alcohol (binder) dissolved in acetone. The amount of cetyl alcohol used was approximately $2 \%$ of the weight of urania powder. The amount of acetone used was $0.25 \mathrm{~mL} / \mathrm{g}$ urania. The urania/alcohol mixture was gently heated with a heat lamp and blended until dry. This material was then passed through a 30-mesh sieve to break up any agglomerates, isostatically pressed at 25 to $30 \mathrm{kpsi}$, then crushed and passed through a 60 -mesh sieve $(250 \mu \mathrm{m})$.

After sieving, approximately $150 \mathrm{~g}$ of the treated urania was loaded into a graphite die and pressed in a Carver 25-ton press for 1 minute at 20 tons of load. The rough pellet was then removed and sintered at $1825^{\circ} \mathrm{C}$ for 4 hours in humidified $\mathrm{H}_{2}\left(45^{\circ} \mathrm{F}\right.$ dewpoint). The pellet was ground to final dimensions and vacuum outgassed at $250^{\circ} \mathrm{C}$ for 2 hours.

\section{B. Source and History of Test Components}

The graphite components used in the test series were obtained from EG\&G Mound Applied Technologies. The converter section was loaded with a stack made up of one FWPF graphite module and two POCO* graphite modules. The POCO modules were located at both ends of the stack, with the FWPF graphite module in the middle. Each of the POCO modules, which were included to provide inertial constraint during the impact, contained two molybdenum cylindrical slugs, each slug having a mass equivalent to a loaded GIS.

The target module was fabricated from FWPF graphite and contained FWPF graphite GISs loaded with urania-fueled GPHSs with flight-quality iridium cladding. Components of the GPHS module stack are identified in Table I.

The module consisting of a FWPF aeroshell contains two GISs: A and C. The A GIS is inserted in the A GIS cavity. This cavity is identified by a small dimple on the aeroshell face that has flight-control bevels machined on the edges. The dimple is located on the corner closest to the A GIS cavity end cap.

The RTG converter shell used in this test was provided by Lockheed Martin Missiles and Space. The converter shell consisted of a representative section of a converter housing and included multifoil insulation surrounding the graphite modules and thermoelectric elements (unicouples) installed in the converter housing. The aluminum plate fragment used in this test was fabricated from a sheet of 7075 aluminum with a T6 temper. The following Lockheed Martin drawings define the articles tested: 23009110 Converter Assembly, 23009100 Shell Assembly, and 23009105 Heat Source Assembly.

*Trade name of POCO Graphite Co. polycrystalline graphite. 


\begin{tabular}{ll}
\hline \hline TABLE I. Test Components & \\
\hline Module ID & 8073 \\
A GIS Assembly & \\
\hline GIS & 2019 \\
Floating Membrane & 4017 \\
GPHS, Open End & SC0126 \\
GPHS, Blind End & SC0125 \\
C GIS Assembly & \\
\hline GIS & \\
Floating Membrane & 2021 \\
GPHS, Open End & 4018 \\
GPHS, Blind End & SC0128 \\
\hline \hline
\end{tabular}

\section{EXPERIMENTAL PROCEDURES}

\section{A. Pretest Data}

The dimensions and weights of the urania pellets were measured and recorded before encapsulation. The clads were then submitted for ultrasonic testing (UT) of the girth weld and the dimensions of the clads recorded. On the basis of the UT results, all of the fueled clads used in this test would be considered acceptable for flight use. Table II lists the weights of the the urania pellets used in this study. Also listed are the clad vent sets and the UT results. Table III lists the clad preimpact dimensions.

TABLE II. Impact Test GPHS Capsules

\begin{tabular}{cccccc}
\hline $\begin{array}{c}\text { GPHS } \\
\text { ID }\end{array}$ & $\begin{array}{c}\text { Postimpact } \\
\text { Containment } \\
\text { Shell No. }\end{array}$ & $\begin{array}{c}\text { Max. UT } \\
\text { Indication } \\
\text { (equil mil) }\end{array}$ & $\begin{array}{c}\text { Indication } \\
\text { Location } \\
\text { (deg) }\end{array}$ & $\begin{array}{c}\text { Pellet } \\
\text { ID }\end{array}$ & $\begin{array}{c}\text { Pellet } \\
\text { Weight } \\
\text { (g) }\end{array}$ \\
\hline SC0125 & 9808-01-A1WN & 5.2 & 56.0 & 09 & 143.930 \\
SC0126 & $9808-01-A 1 W P$ & 4.5 & 7.5 & 10 & 144.170 \\
SC0127 & $9808-01-A 1 W R$ & 4.2 & 131.5 & 13 & 145.330 \\
SC0128 & 9808-01-AIWT & 3.3 & 267.0 & 56 & 149.200 \\
\hline
\end{tabular}




\section{DISCLAIMER}

Portions of this document may be illegible in electronic image products. Images are produced from the best available original document. 


\section{DISCLAIMER}

This report was prepared as an account of work sponsored by an agency of the United States Government. Neither the United States Government nor any agency thereof, nor any of their employees, make any warranty, express or implied, or assumes any legal liability or responsibility for the accuracy, completeness, or usefulness of any information, apparatus, product, or process disclosed, or represents that its use would not infringe privately owned rights. Reference herein to any specific commercial product, process, or service by trade name, trademark, manufacturer, or otherwise does not necessarily constitute or imply its endorsement, recommendation, or favoring by the United States Government or any agency thereof. The views and opinions of authors expressed herein do not necessarily state or reflect those of the United States Government or any agency thereof. 
TABLE III. GPHS Capsules, Preimpact Dimensions

\begin{tabular}{lccc}
\hline Clad ID & Length $(\mathbf{m m})$ & $\begin{array}{c}\text { Vent Cup } \\
\text { Diam }(\mathbf{m m})\end{array}$ & $\begin{array}{c}\text { Shield Cup } \\
\text { Diam (mm) }\end{array}$ \\
\hline SC0125 & 29.97 & 29.74 & 29.74 \\
SC0126 & 29.92 & 29.72 & 29.74 \\
SC0127 & 29.92 & 29.84 & 29.74 \\
SC0128 & 29.92 & 29.74 & 29.79 \\
\hline
\end{tabular}

\section{B. Engineering Testing}

Several engineering tests, designed to determine the effects of various experimental parameters, were conducted at the Sandia National Laboratories (SNL) rocket sled test track area within Area III. An initial test was performed to verify that the desired test velocity, $305 \mathrm{~m} / \mathrm{s}$, could be achieved. The fragment deflected because of the extreme aerodynamic forces and blew out of the attachment clamps at approximately $200 \mathrm{~m} / \mathrm{s}$. In the second test, the same fragment mount bracket was used; however, the fragment was held rigidly to allow membrane forces to develop as the aerodynamic loading increased. The target for this test was a steel cylinder that was supported by four strings to simulate a free restraint. As predicted by a Los Alamos National Laboratory (LANL) hydrocode, the cylinder cut a path through the fragment before momentum was transferred to it. This test verified that the fragment restraint scheme was essentially irrelevant because of the high energy levels of the impact.

An alternative approach in which the converter was accelerated and the fragment held stationary theoretically would produce a collision with the same energy exchange without extreme aerodynamic forces being placed on the fragment. To validate this thesis, two aluminum cylinders with fins were fabricated to simulate converter housings for additional tests. In the third engineering test, a mock converter housing was mounted on an SNL utility sled attachment and impacted into a fragment that was minimally supported by small wooden dowels. Both the fragment and the mock converter failed. The failure of the fragment was not as catastrophic as in the second engineering test; the converter was completely severed.

The fourth test reversed the roles of the two components in the third test. The fragment was restrained, as in the second test, and the converter was supported against a steel ring that had semirigid support, with little resistence to deflection. The results were very similar to those of the third test. The converter was penetrated by the fragment and sustained failure over $80 \%$ of its circumference. The fragment failed almost identically. At this point, the test scheme was defined as the acceleration of a rigidly held fragment into a stationary simulant converter housing assembly supported in a semirigid mounting scheme.

The fifth test consisted of accelerating the specified fragment (dimension and material specification) at $305 \mathrm{~m} / \mathrm{s}$ into a soft target. The fragment deflection was 
videotaped with a camera mounted on the sled. The Styrofoam target was marked to provide a reference for the impact point. This test measured the amount of fragment deflection, and the data was used in later tests to align the fragment for the desired impact point on the converter housing assembly.

The sixth test was the final engineering test. An aluminum cylinder with fins welded to its exterior was used. A POCO block, with dimensions equal to three stacked modules and loaded with a molybdenum slug with mass equivalent to that of 12 fueled clads, was loaded into this cylinder. The graphite block was heated in a furnace to approximately $1225^{\circ} \mathrm{C}$, then lowered from the furnace into the simulant RTG converter housing. The fragment support was aligned so that the plate centerline, with aerodynamic forces causing upward deflection of the plate as it was propelled by the rocket sled, would impact the center of the cylinder.

The fragment impacted the cylinder at $302 \mathrm{~m} / \mathrm{s}$. The cylinder tore through the fragment, although the fragment did partially penetrate the cylinder, leaving a large dent and cut. The cut was centered approximately $105 \mathrm{deg}$ from the impact face and extended from approximately 90 to $120 \mathrm{deg}$.

Pieces of graphite were ejected from the top of the cylinder, but most of the graphite and the molbdenum slug remained in the cylinder. Pieces of the fragment and graphite were scattered up to approximately $4.5 \mathrm{~m}$ from the impact point, but most were within $1.5 \mathrm{~m}$. The results of this test confirmed the operation of the furnace, stack-lowering apparatus, converter housing assembly supports, and sled fragment support bracket, and they confirmed the pretest alignment of the fragment.

\section{Field Testing}

The field tests were conducted at the SNL rocket sled test track. The test hardware consisted of the furnace and its support stand and the rocket sled. The furnace, designed to heat its contents in an argon atmosphere, had Canthol elements that were conditioned to reach $1200^{\circ} \mathrm{C}-1250^{\circ} \mathrm{C}$. The furnace had a bottom door that could be remotely operated to allow the graphite stack to be lowered from the furnace into the converter housing. The support stand was a steel structure. It supported the furnace, the apparatus for lowering the graphite stack, and the converter housing assembly. The converter assembly was held in place by four rods and a steel ring plate attached to the bottom of the support stand's platform. The aluminum fragment (7075-T6) that impacted the converter housing edge-on was mounted on the rocket sled (Figure 2). The aluminum fragment was $0.16 \mathrm{~cm}$ thick by $20.32 \mathrm{~cm}$ deep and had an unsupported span (impact edge) of $58.42 \mathrm{~cm}$. The fragment support was aligned so that the plate centerline was $4.92 \mathrm{~cm}$ below the center of the converter housing (Figure 3). This offset compensated for the upward displacement of the fragment plate due to aerodynamic forces placed on the plate as it was propelled on the rocket sled toward the impact target. The amount of displacement was measured during engineering trials with the sled. 


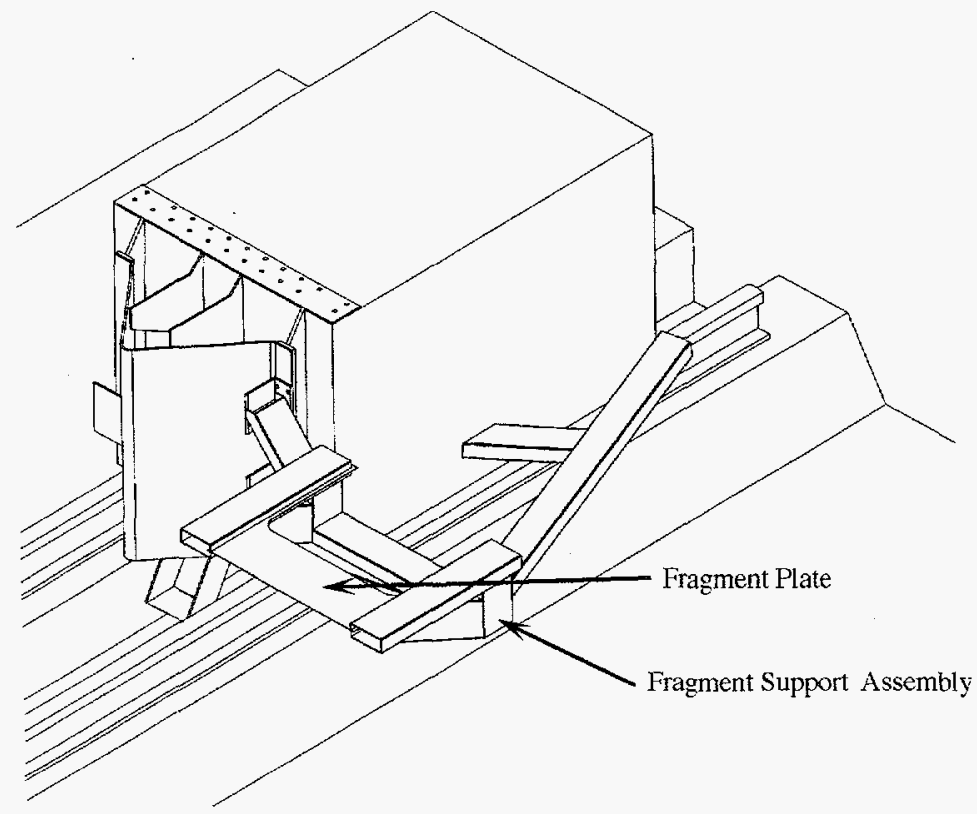

Figure 2. Aluminum fragment mounted on a support bracket on the side of the sled.

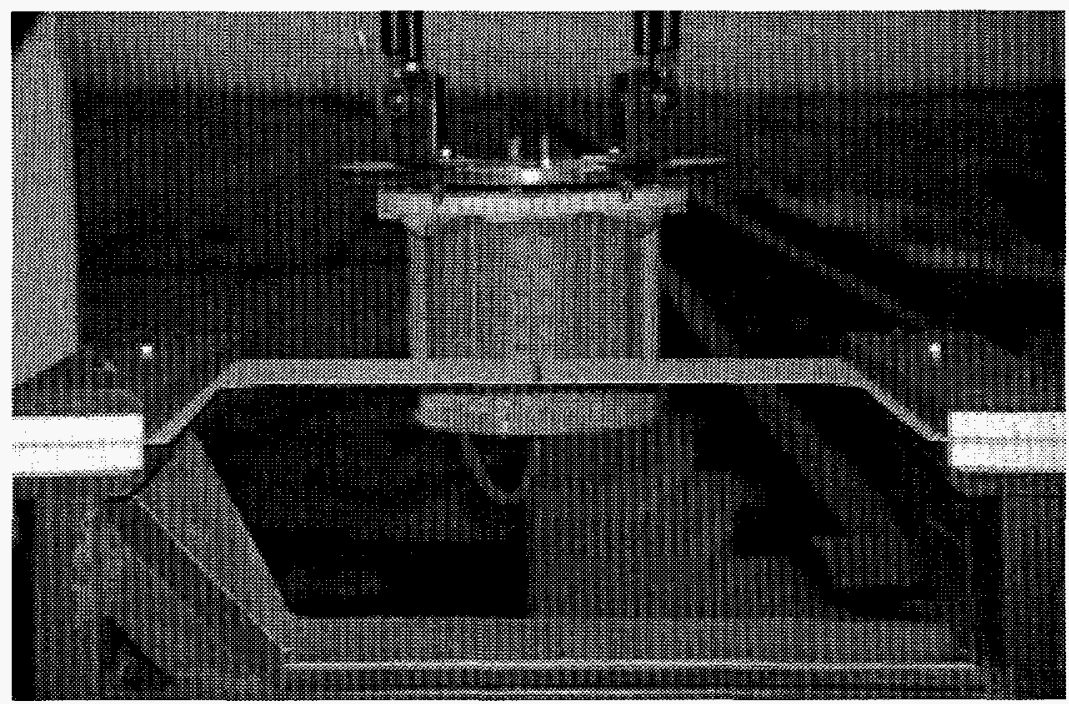

Figure 3. Test alignment of the plate with the converter housing. (Neg E-29)

LANL drawings used for the test assembly included the following:

26Y-318096D1

26Y-318084D1

26Y-318087D1

26Y-318098D1
Side-On Fragment Test Layout

Furnace Assembly

Furnace Support Stand Assembly

Fragment Support Assembly 
The graphite module stacks were heated to approximately $1225^{\circ} \mathrm{C}$. The rockets were readied, and the test sequence began with the remote opening of the furnace door. The stack was then remotely lowered from the furnace into the RTG housing (Figure 4). The fueled clads in the heated stack cooled to approximately $1090^{\circ} \mathrm{C}$ in the time required for the stack to be lowered into the converter housing and impacted by the fragment. This sequence was carefully timed, and the rocket sled was launched 140 seconds after stack placement initiation. The stack cooling characterisistics were measured before testing at LANL and at the SNL test site.

\section{RESULTS}

A representative section of a GPHS RTG with a simulant heat source stack made up of an FWPF module loaded with urania-fueled clads and POCO modules loaded with molybdenum slugs was impacted by an aluminum plate on March 26, 1996. The measured impact velocity was $306 \pm 1.5 \mathrm{~m} / \mathrm{s}$, and the RTG graphite module stack temperature was $1090^{\circ} \mathrm{C} \pm 10^{\circ}$. Figure 5 shows the entire furnace stand; Figure 6 shows the converter housing suspended from the furnace stand platform

High-speed photography of the impact indicated that the plate's leading edge impacted approximately $0.63 \mathrm{~cm}$ above the converter's midpoint. The fragment penetrated the converter shell, microfoil insulation, thermoelements, and GPHS graphitics and contacted a fueled clad. The converter was cut and torn over approximately $80 \%$ of its

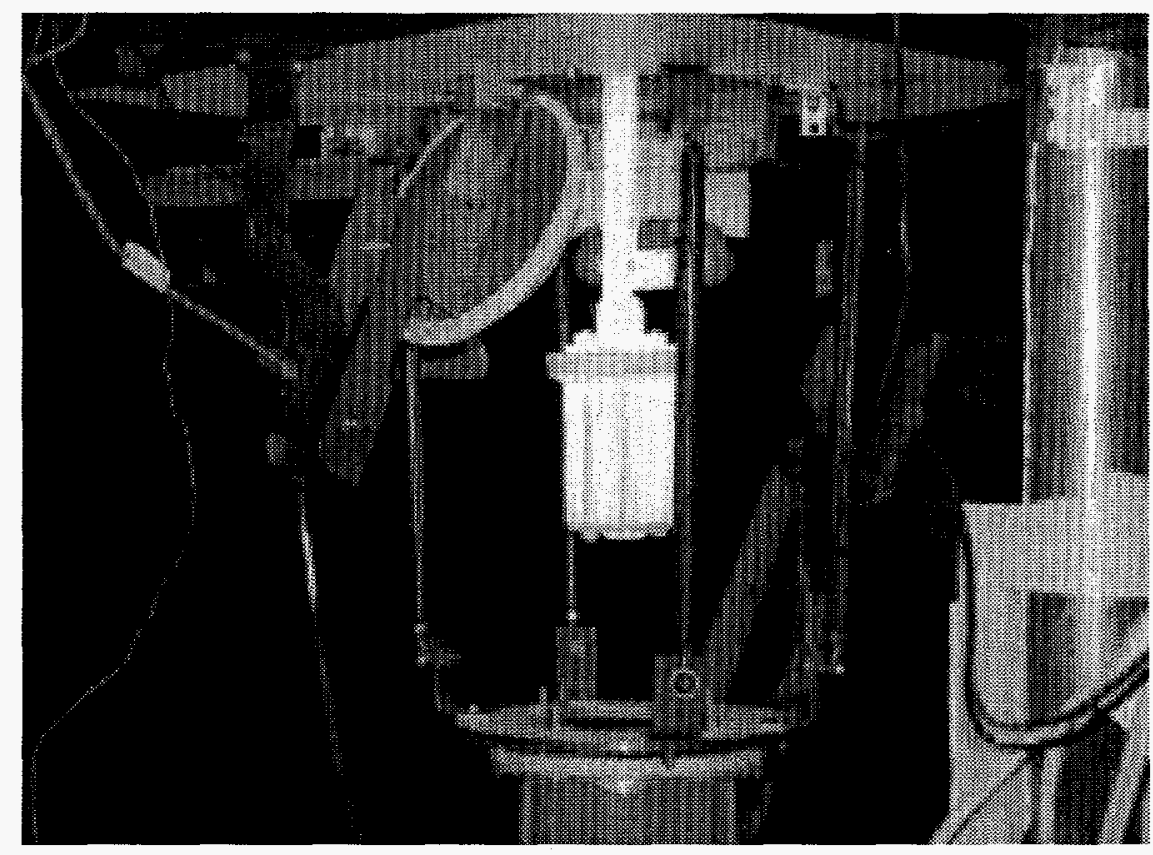

Figure 4. The heated stack being lowered into the converter housing. (Neg D-13) 


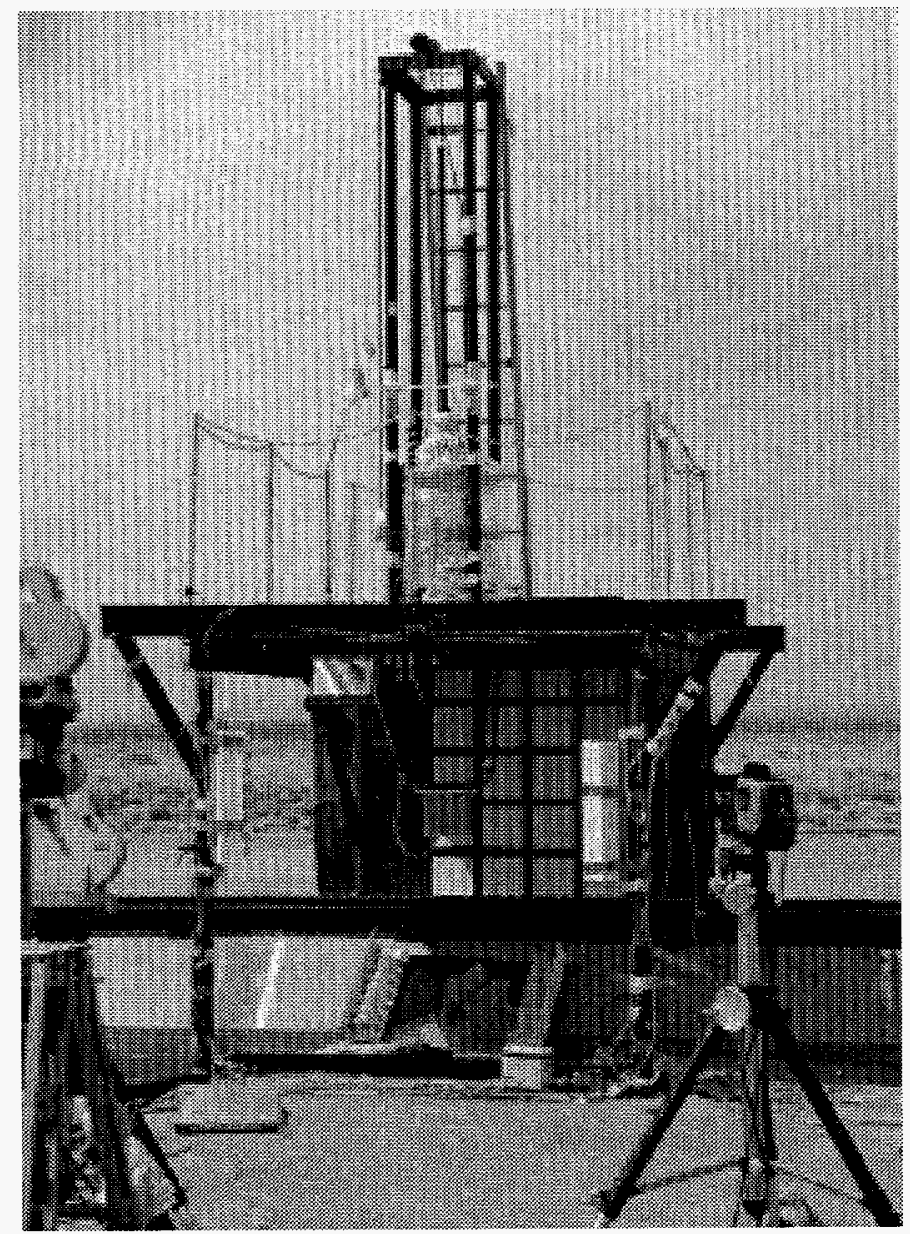

Figure 5. Test stand for the RTG-3 test.

(Neg B2322, Roll 1, \#15)

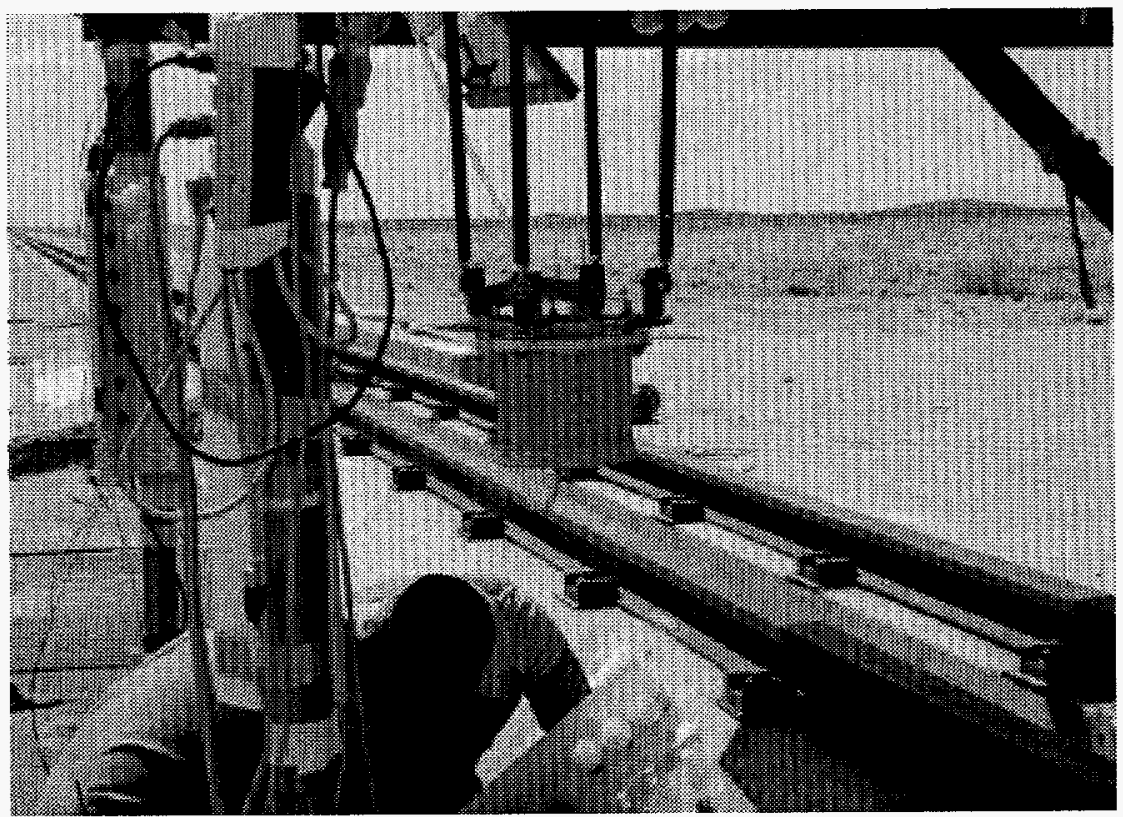

Figure 6. The converter housing suspended from the test stand platform for RTG-3. (Neg B2322, Roll 1, \#11) 
circumference (Figure 7). The width of the gap was approximately $2 \mathrm{~cm}$. The cut was clean at its upper edge, but the lower edge was folded over, toward the inside of the shell. Radiological surveys of the converter's outer surface and the impact vicinity conducted immediately after the impact indicated that no urania was released from the converter.

The top of the converter housing showed indications that materials within the housing were ejected though the top opening (Figure 8). One of the POCO graphite modules was ejected out of the top of the converter and was found lying a few feet away (Figure 9). Lying directly next to the ejected module was a molybdenum slug that was ejected from that module. The other slug that had been loaded into the module was also ejected and came to rest within a few feet (Figure 10). The module was intact but chipped. Preliminary field observations revealed no cracks. Other pieces of graphite were also observed in the impact area and appeared to have come from the top part of the graphite stack (Figure 11). A few pieces of FWPF graphite were also found.

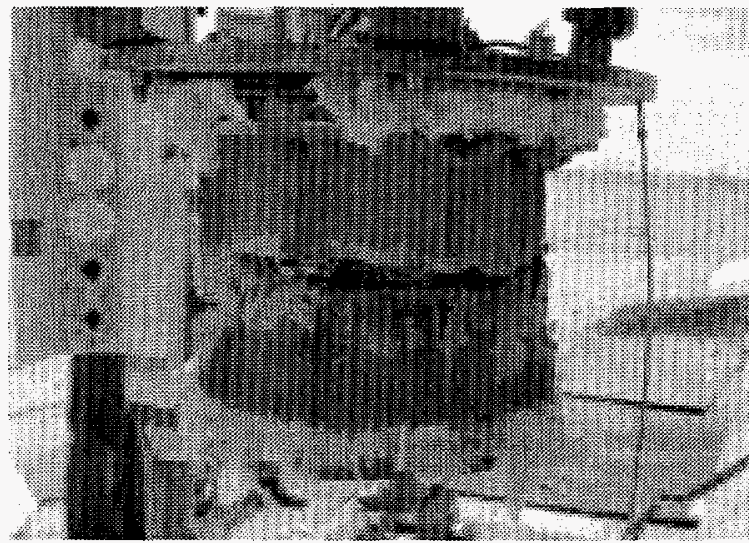

(a)

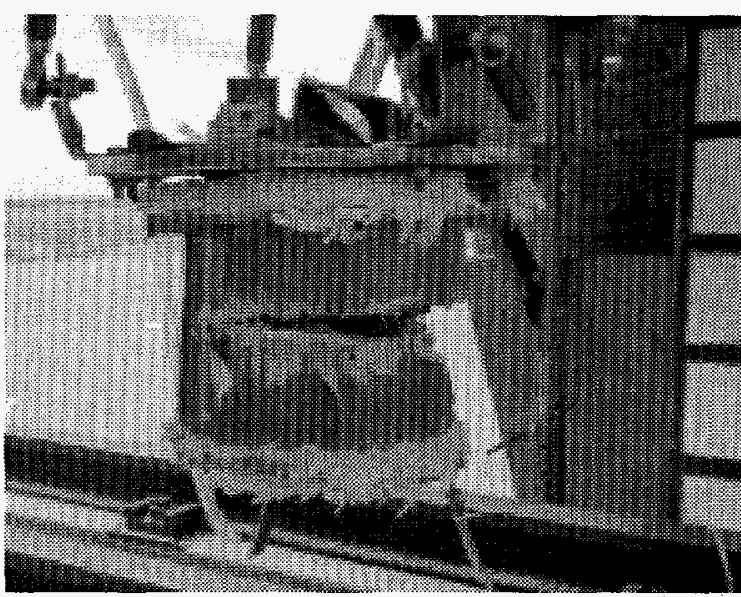

(c)

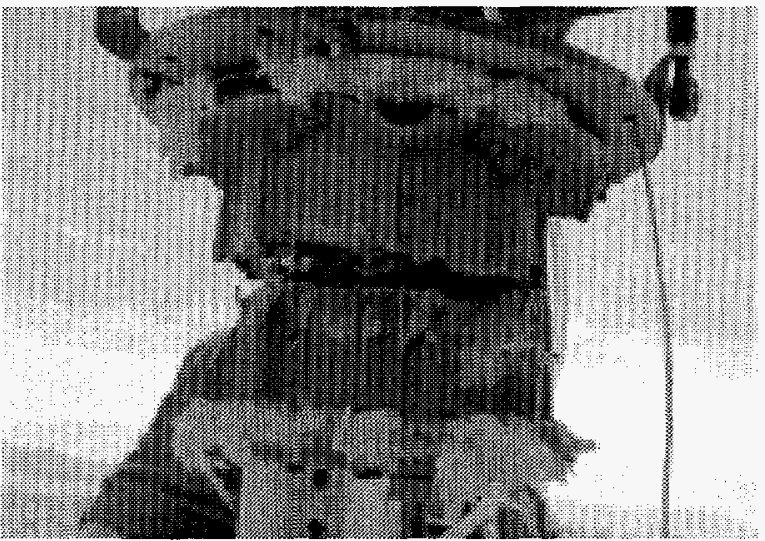

(b)

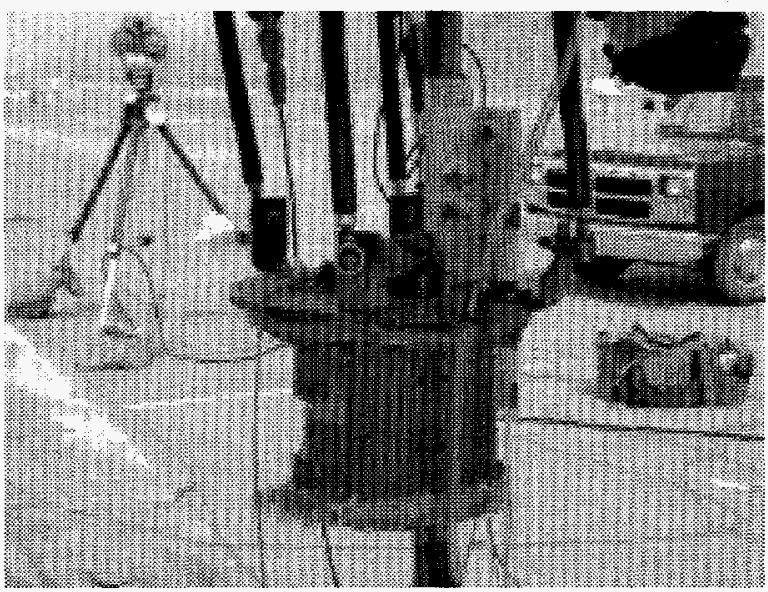

(d)

Figure 7. The impacted converter housing: (a) impact face, (b) profile, (c) opposite profile, and (d) trailing face. (Neg B2322, Roll 2, \#5; Roll 1, \#26, 21, and 36) 


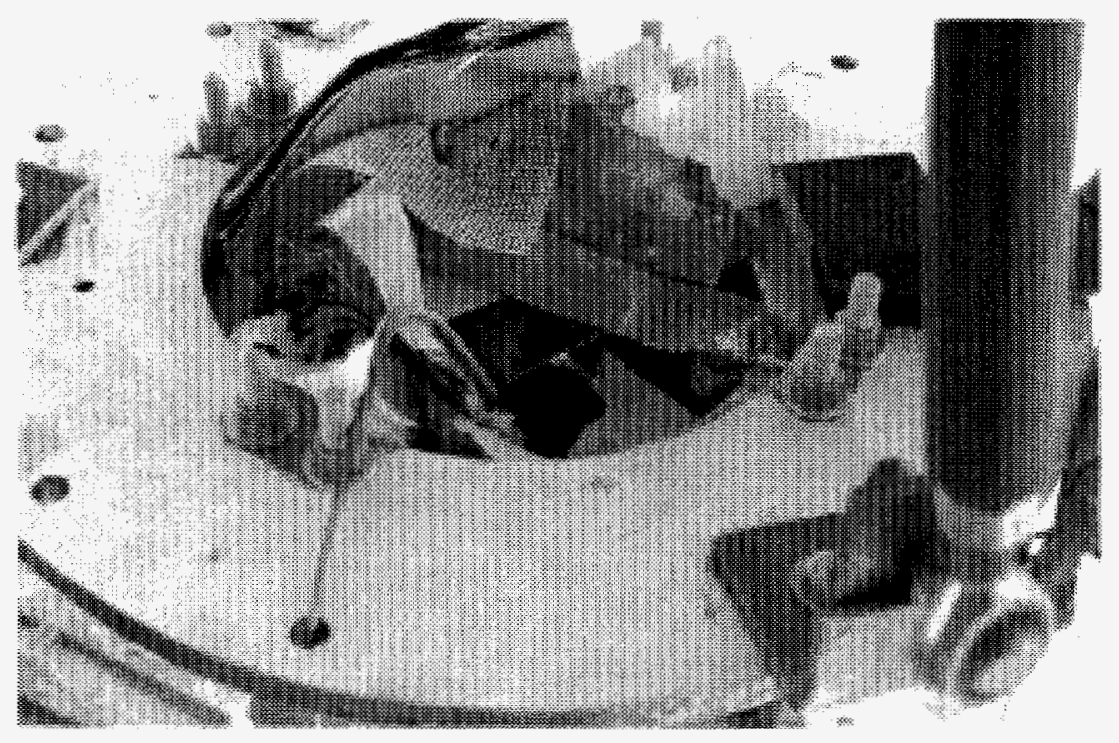

Figure 8. Top of the converter housing, postimpact. (Neg B2322, Roll 1, \#28)

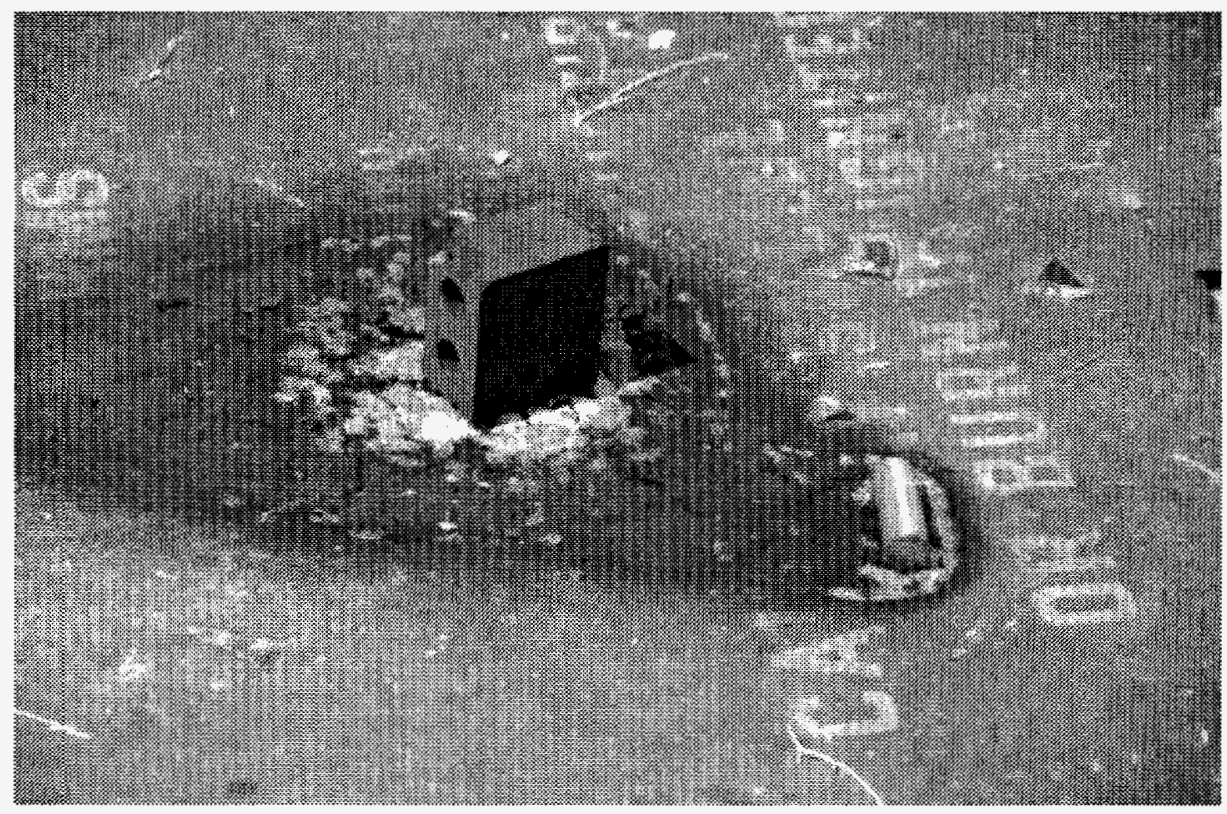

Figure 9. Ejected POCO graphite module with an ejected molybdenum slug. (Neg $\mathrm{H}-3$ ) 


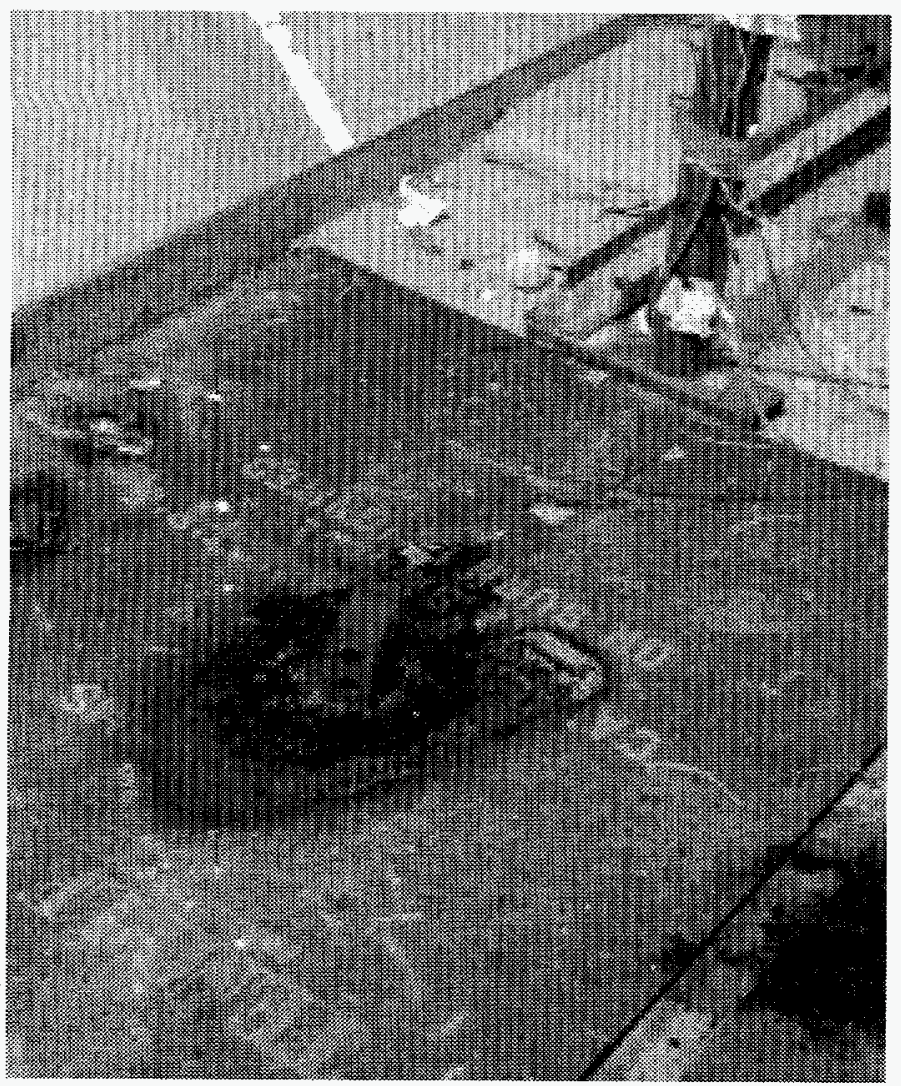

Figure 10. Ejected POCO graphite module with ejected molybdenum slugs. (Neg B2322, Roll 2, \#15)

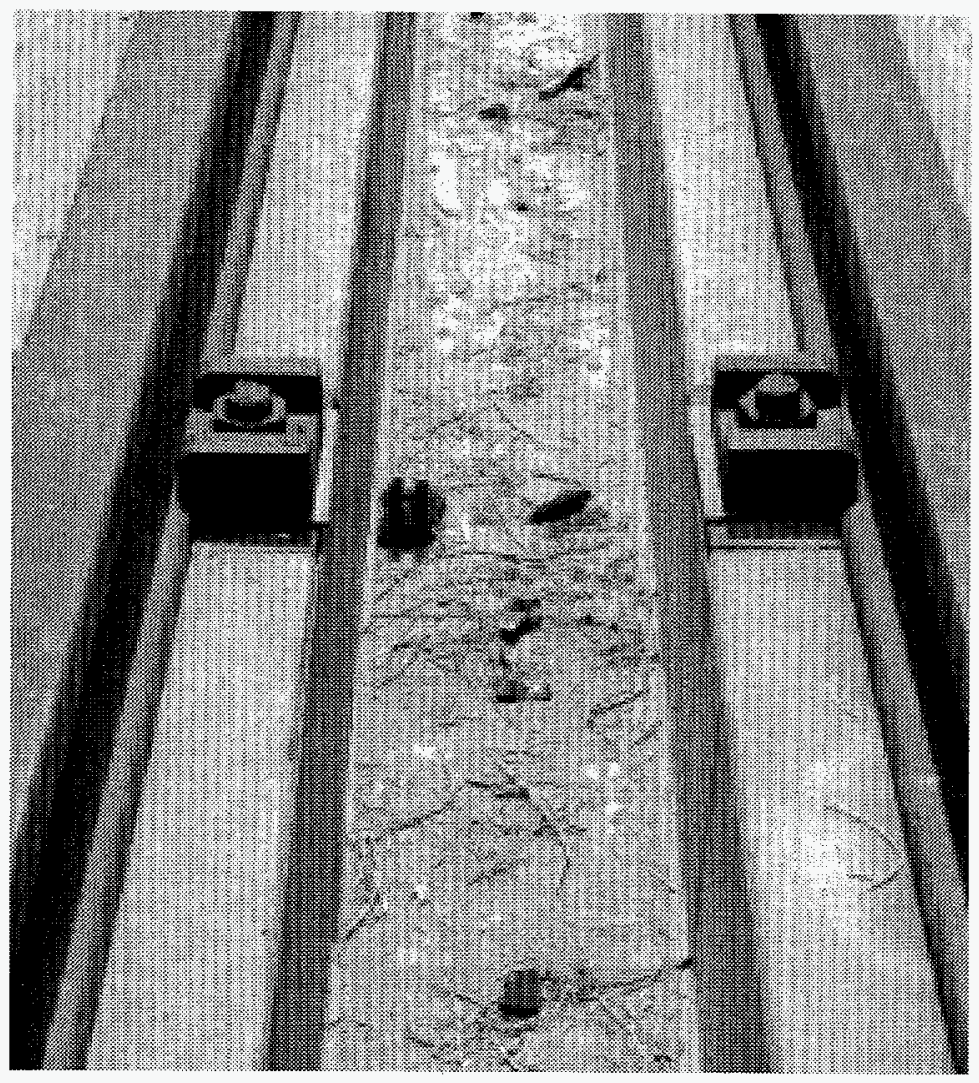

Figure 11. Ejected pieces of graphite (center of the photograph, between the sled rails) that appear to have come from the top of the test stack. (Neg B2322, Roll 2, \#8). 
A relatively large piece of the fragment was torn from the sled (Figure 12). This piece, roughly trapezoidal, measured approximately $23 \mathrm{~cm}$ at the leading edge and $39 \mathrm{~cm}$ at the trailing edge. This piece was not recovered whole but represented the sum of several relatively small fragments. Most of these fragments were scattered outside the converter housing, but a few fragments were seen inside the converter during preliminary investigation.

Postmortem examination of the test components began at Los Alamos on April 4, 1996. All graphite and aluminum fragment pieces that were recovered outside the converter were gathered together and photographed. Graphite recovered outside the converter consisted primarily of graphite components from the top of the graphite stack,

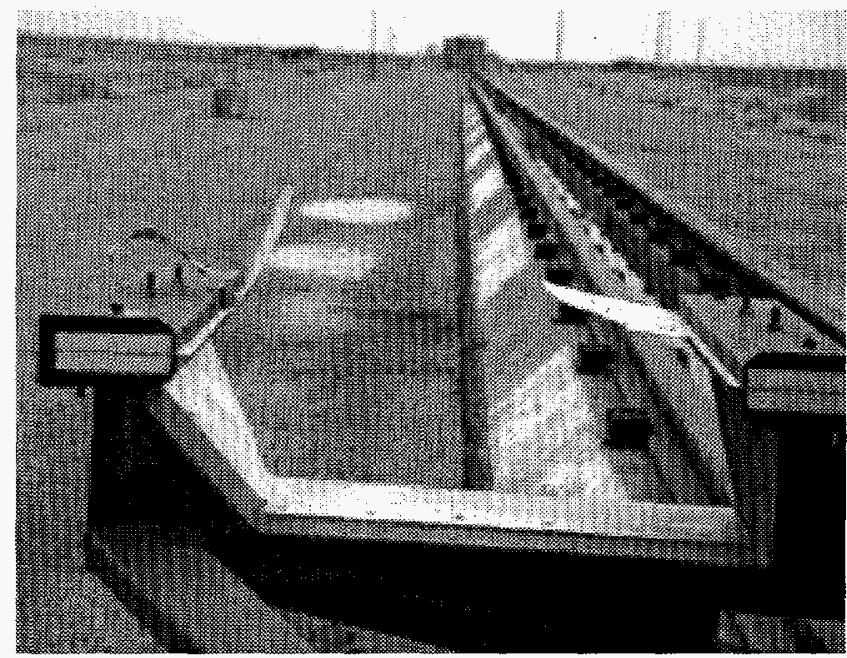

(a)

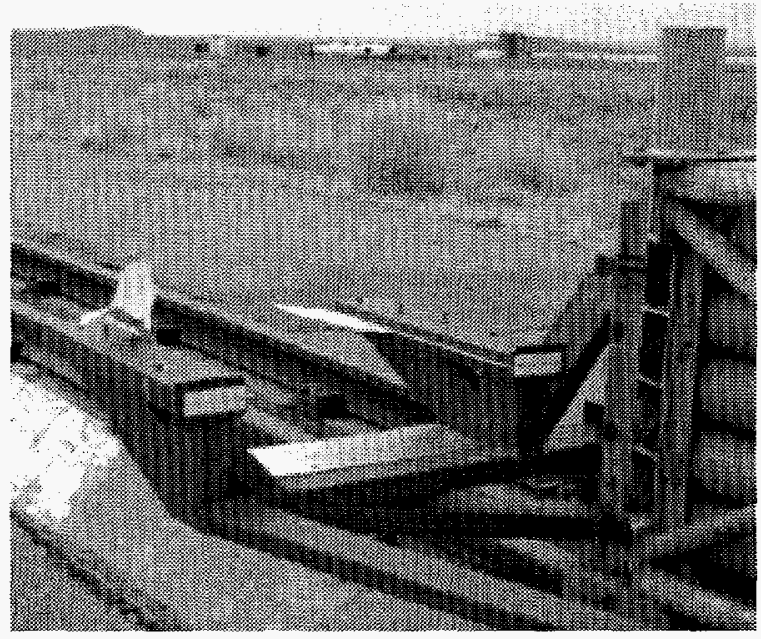

(b)

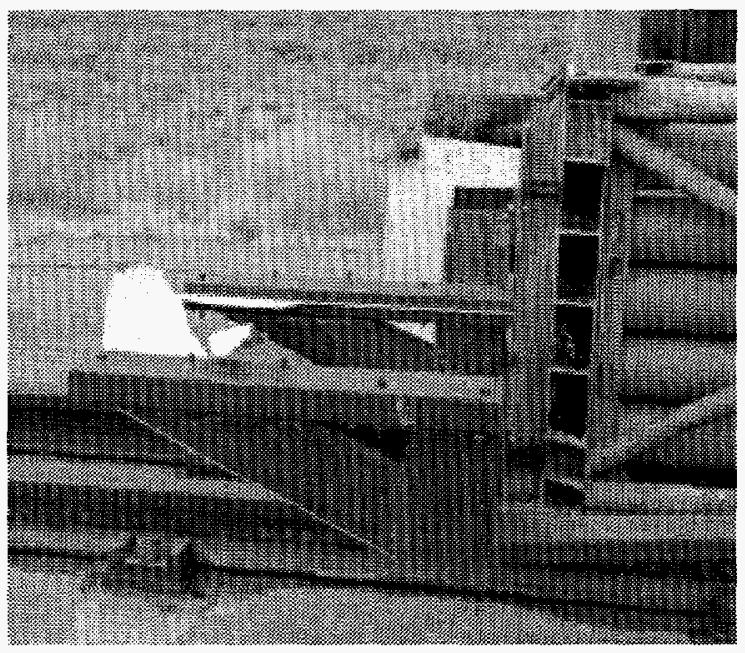

(c)

Figure 12. A relatively large piece of the thin plate was torn from the sled: (a) view from the back of the sled, (b) view from an angle, and (c) profile. (Negs 1-34; B2322, Roll 2, \#35 and 34). 
including the stack-lifting lug and the top POCO module (Figure 13). Graphite recovered from inside the converter consisted of the bottom POCO module and bottom support pieces (Figure 14) and the FWPF module (Figure 15). One molybdenum slug was totally dislodged from the bottom module; the other was partially dislodged. The aluminum plate fragments recovered outside the converter were severely deformed, as were the fragments recovered from the converter interior (Figure 16). Approximately three-fourths of the fragments recovered from the converter interior had melted and resolidified.

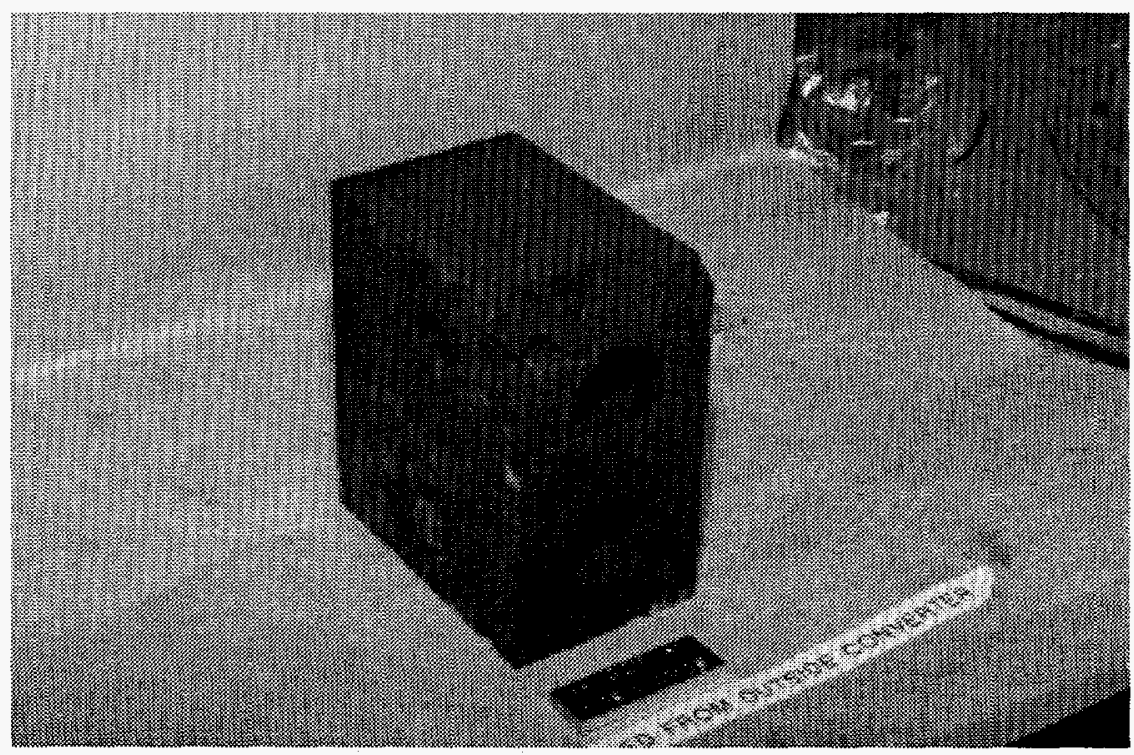

(a)

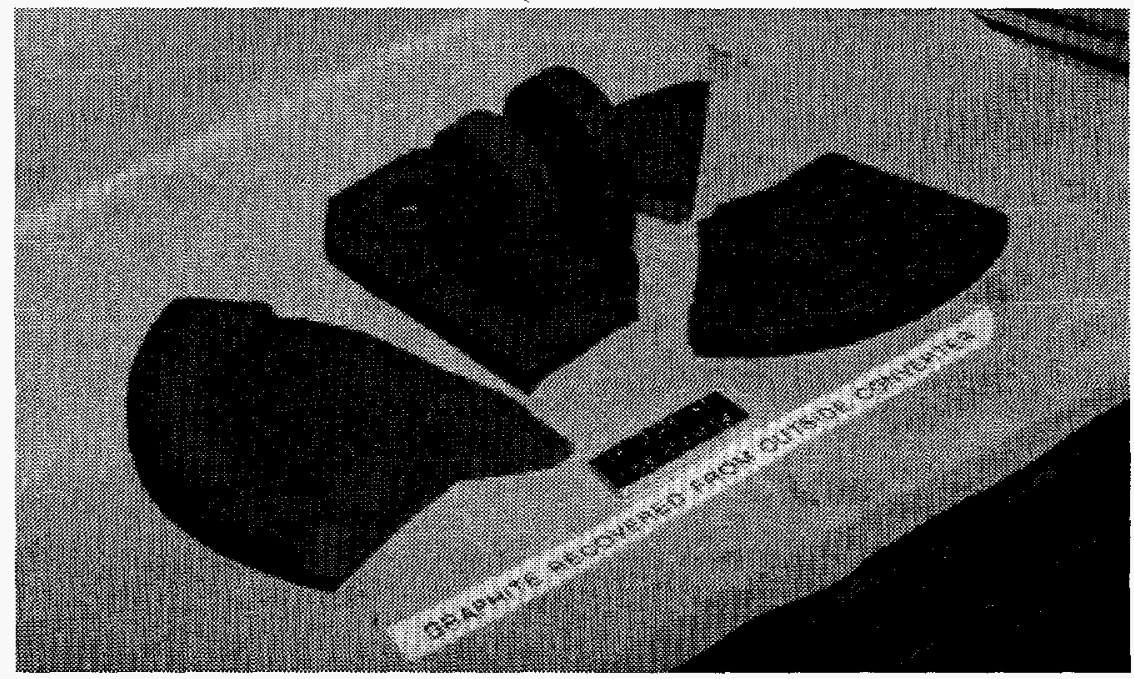

(b)

Figure 13. Graphite components recovered at the test site and found outside the converter housing: (a) the top of the POCO module and (b) the stacklifting lug and other recovered pieces. (Neg B2323, Roll 5, \#29 and 27) 


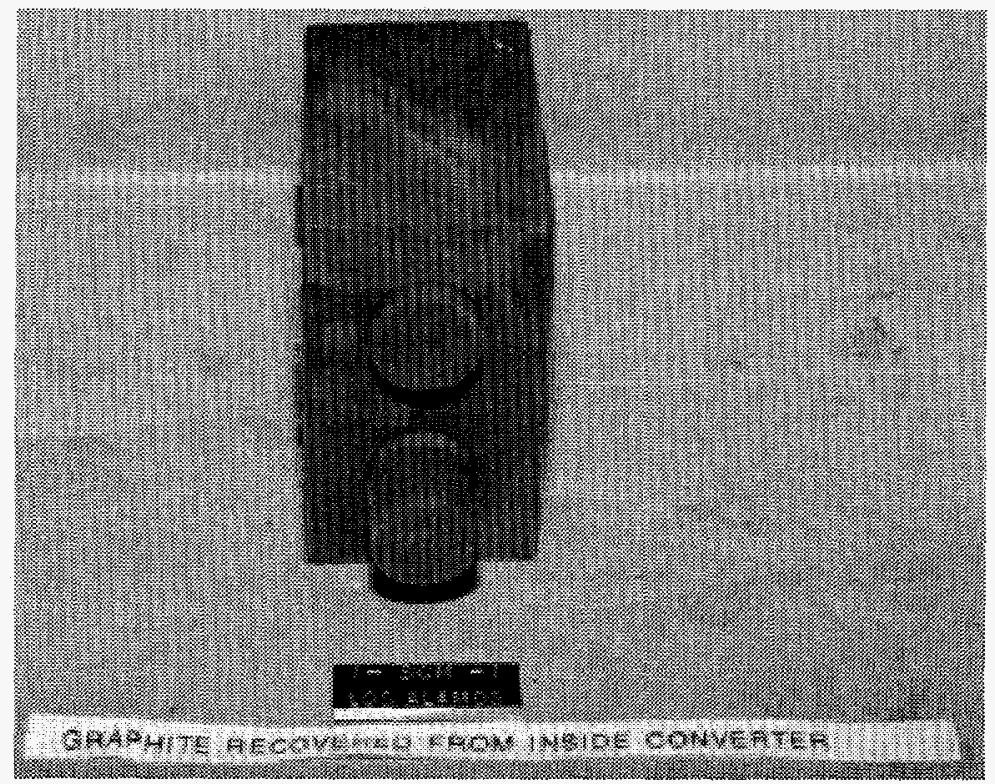

(a)

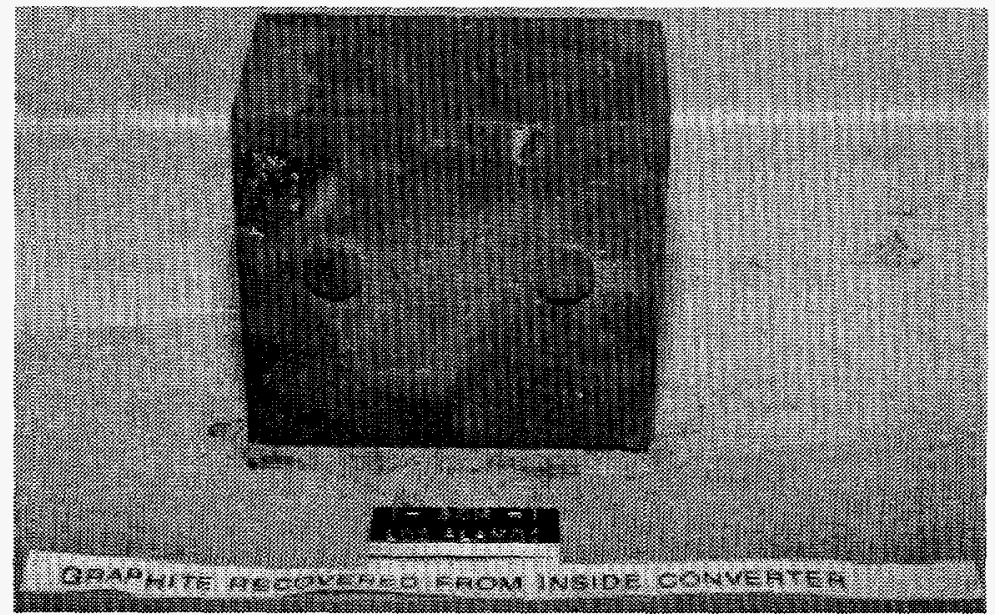

(b)

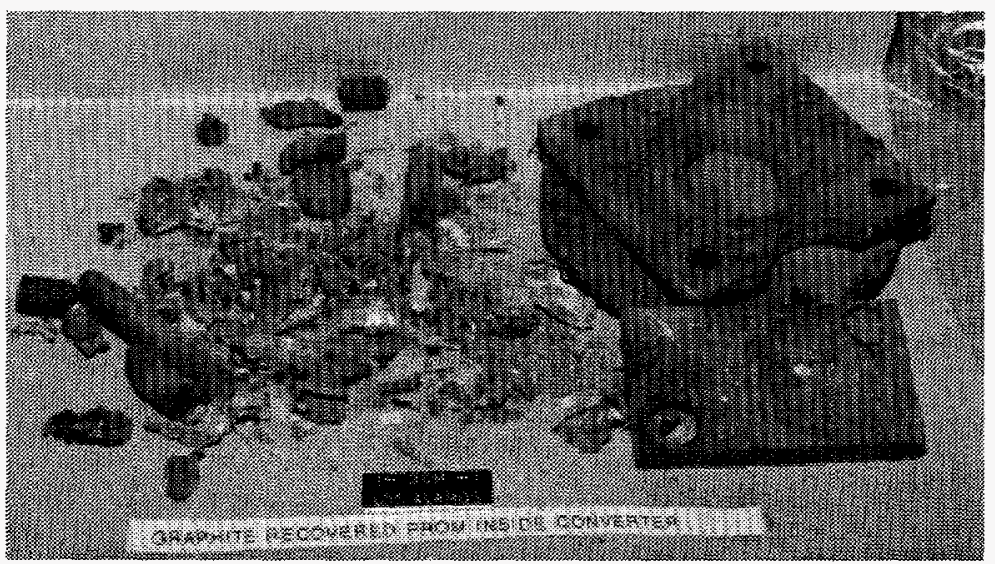

(c)

Figure 14. POCO graphite components recovered from the converter interior: (a) end view of the bottom of the POCO module, (b) profile of the bottom of the POCO module, and (c) graphite bottom support pieces and miscellaneous shattered graphite pieces. (Neg B2323, Roll 5, \#34 and 36A; Roll 6, \#1). 


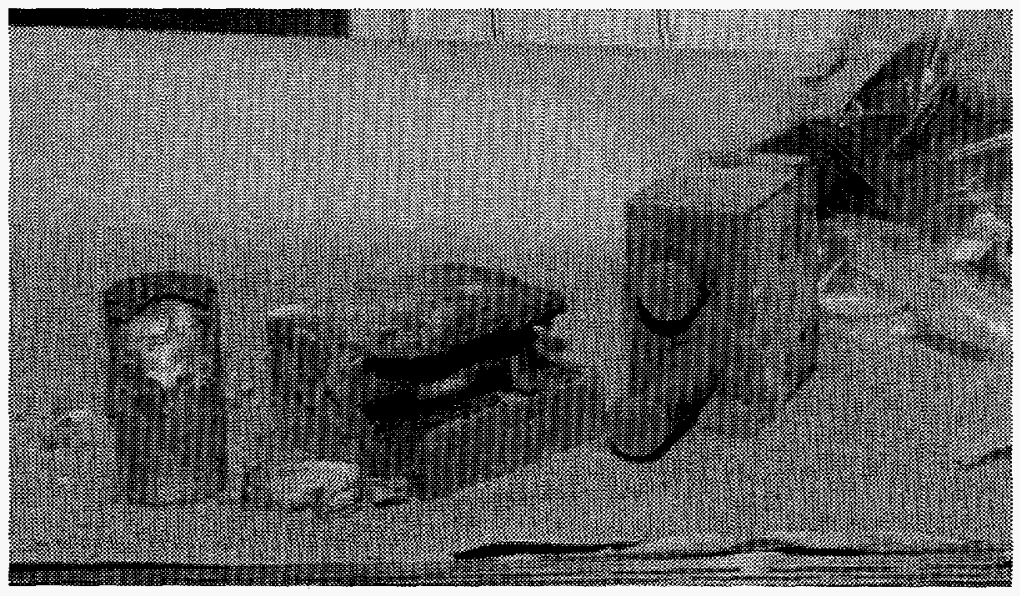

Figure 15. POCO module and FWPF module (the ejected GIS A to the left) recovered from the converter interior. (Neg B2323, Roll 1, \#15)

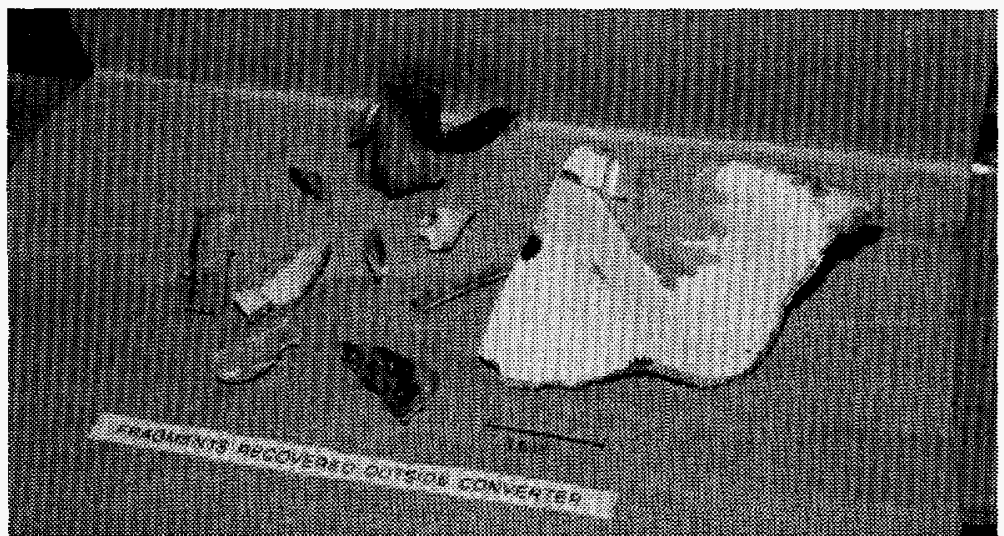

(a)

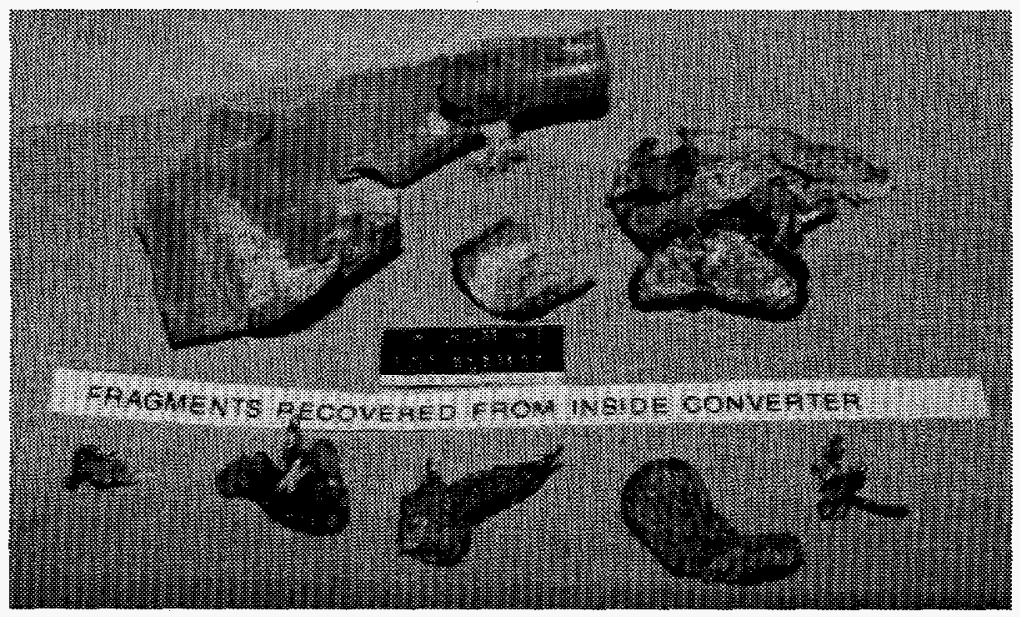

(b)

Figure 16. Aluminum fragments recovered from the impact test: (a) fragments recovered outside the converter and (b) fragments recovered from the converter interior. (Neg B2323, Roll 5, \#3 and 10) 
Posttest disassembly of the converter revealed that the leading edge of the fragment, which was roughly parallel to the long axis of the A GIS, penetrated into the A GIS cavity of the target GPHS module (Figure 17). One corner of the module, at the GIS cavity, was sheared off. The graphite module cap of this cavity was dislodged and had a gash that was apparently caused by penetration of the aluminum plate. The A GIS was ejected from the module. One-half of the GIS end cap had been severed from the GIS; the other half remained in place. A relatively large piece of the GIS at the impact area (approximately one-quarter of the top end) had been sheared off. Neither clad had been dislodged from the GIS. The open-end clad was breached on its shield cup (SC0126). Further disassembly revealed no other breaches in the remaining clads. The C GIS was unbreached and totally intact. Figure 18 shows an expanded layout of the FWPF module and its contents. Capsule deformations are listed in Table IV.

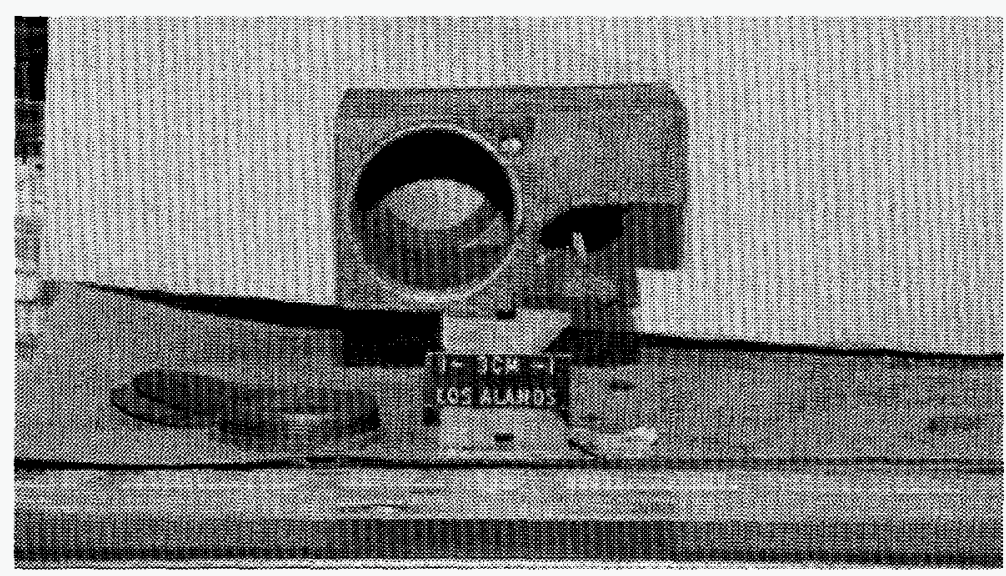

Figure 17. End view of the FWPF module showing a gash apparently caused by the impact of the plate with the A GIS cavity of the module. (Neg B2323, Roll 3, \#11)

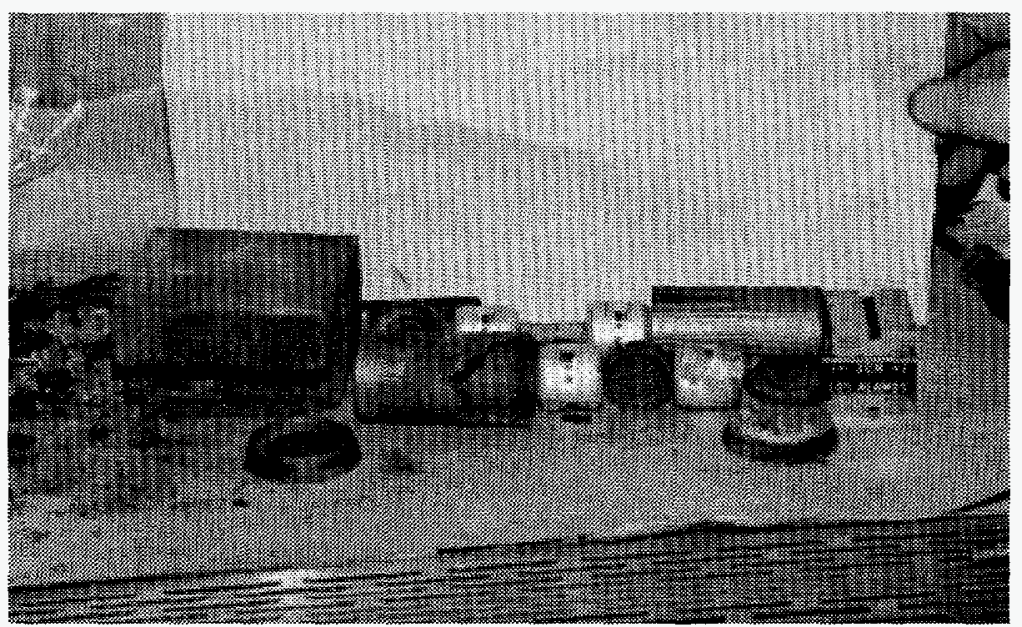

Figure 18. Expanded layout of the FWPF module and its contents. (Neg B2323, Roll 4, \#36). 
TABLE IV. Capsule Strains (\%)

\begin{tabular}{lccccc}
\hline & & \multicolumn{2}{c}{ Vent Cup, Diametral } & \multicolumn{2}{c}{ Shield Cup, Diametral } \\
\hline GPHS & Axial & \multicolumn{1}{c}{ Max. } & Min & Max. & Min \\
\hline SC0125 & 0.5539 & 0.5044 & -1.1432 & 0.7734 & -1.1769 \\
SC0126 & 3.8102 & 0.7066 & -1.2113 & 1.3786 & -1.1769 \\
SC0127 & 0.5682 & -0.5027 & -0.9383 & -0.1345 & -0.2017 \\
SC0128 & 0.7019 & -0.2690 & -1.0424 & -0.3693 & -0.8392 \\
\hline \hline
\end{tabular}

Capsule SC0126, which was located at the open end of the A GIS, had a small transverse breach ( $1.84 \mathrm{~mm}$ long, $0.40 \mathrm{~mm}$ wide) that was apparently caused by impact with the plate fragment (Figure 19). This breach was located between approximately 200 and $220 \mathrm{deg}$ on the shield cup knuckle. Melted aluminum and material that appeared to be an $\mathrm{A} 1 / \mathrm{Ir}$ reaction product surrounded the breach. This material was also observed on the capsule in several locations. Upon further investigation, this single breach was found actually to consist of two separate failures. During examination, fragments of the aluminum fragment that partially covered these clad failures began to flake off. Subsequent meaurement revealed that this material had covered breaches that were larger than the initial measurement taken. One breach was circle shaped and measured approximately $2.1 \mathrm{~mm}$ in diameter (3.41- $\mathrm{mm}^{2}$ breach area). The other breach measured approximately $3.68 \mathrm{~mm}$ long and $0.56 \mathrm{~mm}$ at its widest point (approximately $2.06 \mathrm{~mm}^{2}$ breach area). Two other transverse hairline cracks were seen on the shield cup. One crack measured approximately $7.92 \mathrm{~mm}$ long and was located below the weld at approximately $115 \mathrm{deg}$ from the weld start carets. The other crack was located at approximately $350 \mathrm{deg}$, on the cup knuckle, and measured approximately $3.58 \mathrm{~mm}$. An atypical discoloration of the clad material was observed approximately $130 \mathrm{deg}$ from the weld carats. The estimated amount of fuel released from the capsule was $0.0890 \mathrm{~g}$ (based on the weight of recovered fuel retained by the capsule).

Because SC0126 was the most severely affected capsule, it was selected for metallographic analysis. It was defueled and the fuel submitted for particle-size analysis. Twelve sections were cut from SC0126 and submitted for metallographic examination. The microstructure of the single-pass weld region was typical. The microstructure of the weld overlap region was somewhat atypical, with modest thinning of the weld centerline cross section and a relatively wide heat-affected zone (Figure 20 ). The grain size in the singlepass weld area averaged 12.0 grains/wall thickness, and the grain size in the weld overlap area averaged 8.5 grains/wall thickness. The microstructures of the vent and shield cup walls were typical. The grain sizes in these areas are given in the Table V. The fuel particle-size analysis is given in Table VI. 


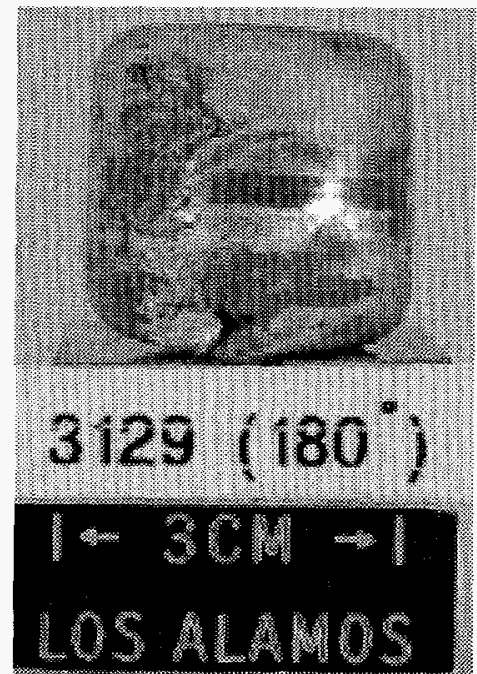

(a)

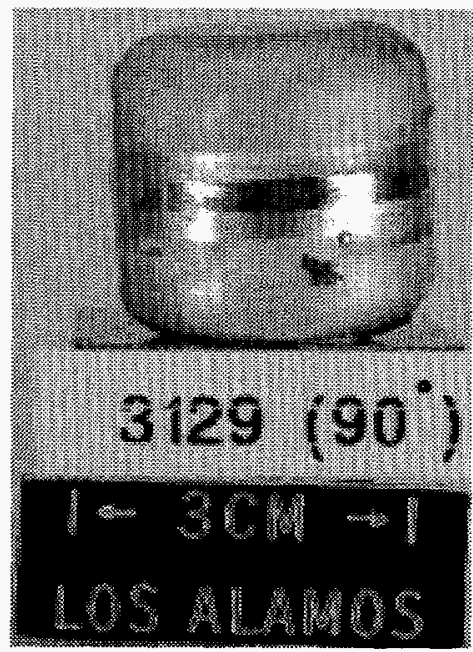

(d)

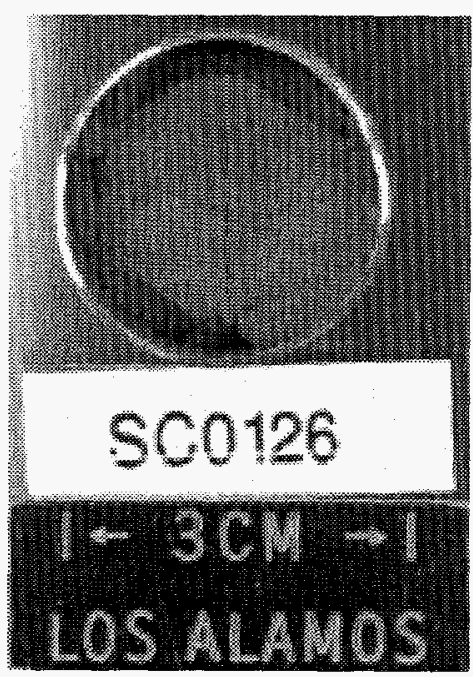

(g)

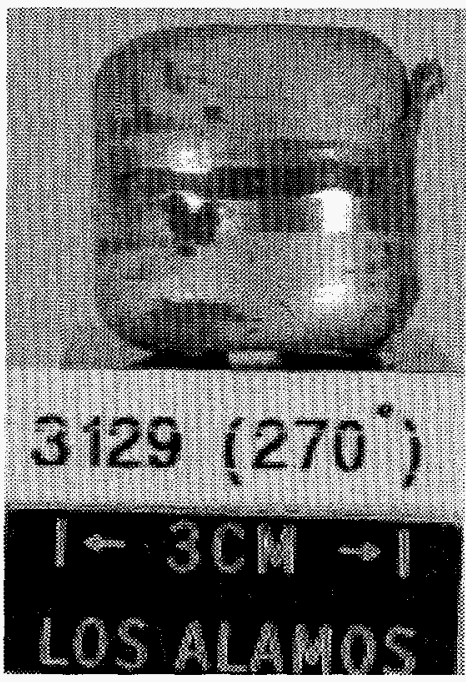

(b)

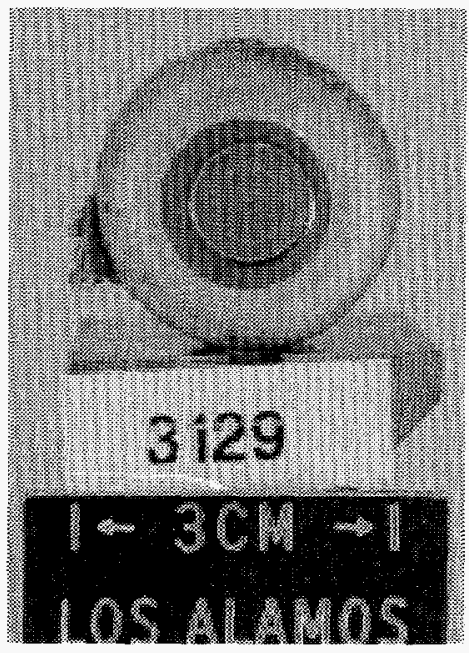

(e)

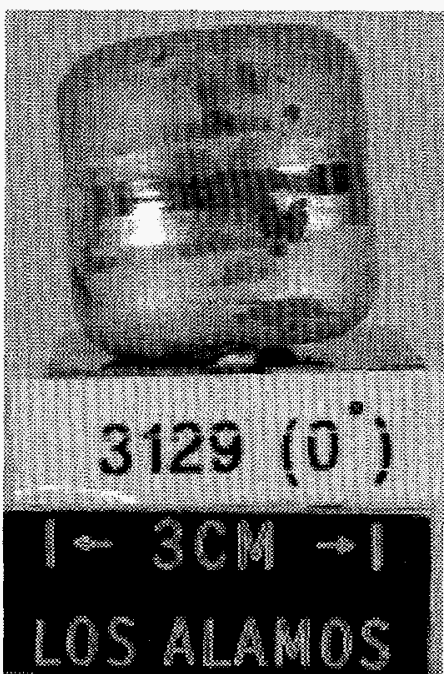

(c)

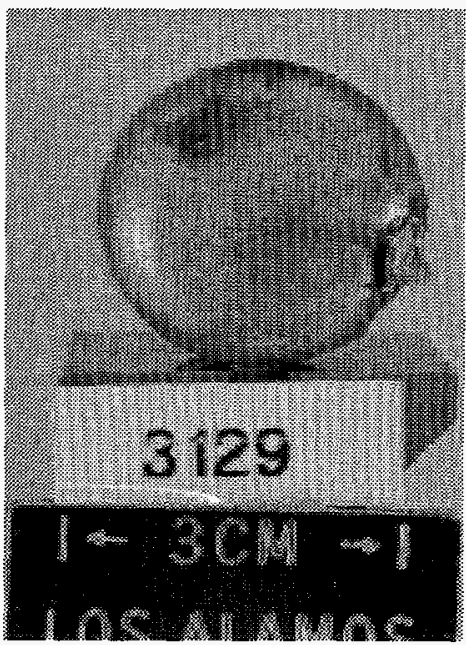

(f)

Figure 19. Capsule SCO126 was the only capsule with breaches in test RTG-3: (a) impact face, (b) profile, (c) trailing face, (d) opposite profile, $(e)$ vent end, $(f)$ blind end, and $(g)$ fuel fragmentation. (NMT-9 Negs SC126M12, SC126M13, SC126M10, SC126M11, SC126M8, SC126M9, and SC126M15) 


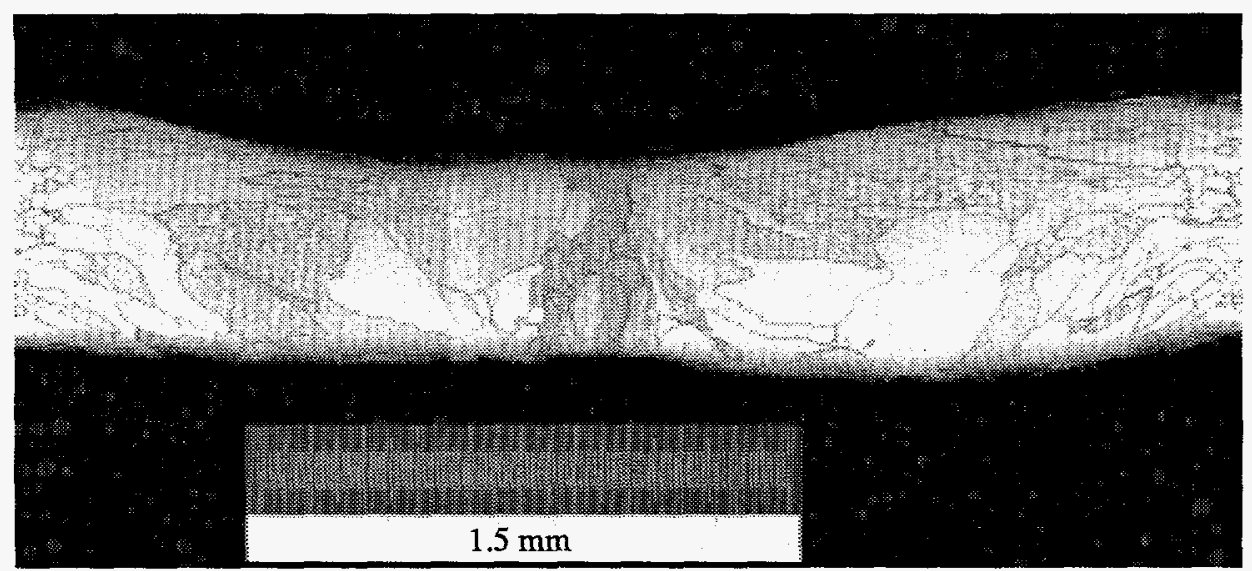

Figure 20. The microstructure of the weld overlap region was atypical. (Negs SC126-1-2 and $-1-3$, combined)

Table V. Vent and Shield Cup Microstructure, SC0126

\begin{tabular}{lcc}
\hline Area/Orientation & Grain Size (grains/wall thickness) & Grain Size $(\mu \mathrm{m} / \mathrm{grain})^{\mathbf{a}}$ \\
\hline Shield Cup/Axial & 26.1 & 24.9 \\
Shield Cup/Transverse & 25.0 & 26.0 \\
Vent Cup/Axial & 27.4 & 23.7 \\
Vent Cup/Transverse & 25.9 & 25.1 \\
\hline a'Grains/nominal wall thickness of $0.65 \mathrm{~mm}$. & \\
\hline \hline
\end{tabular}

TABLE VI. Particle-Size Analysis of Urania Recovered from RTG-3

\begin{tabular}{cc|cc}
\hline $\begin{array}{c}\text { Particle Size Range } \\
(\mu \mathrm{m})\end{array}$ & $\begin{array}{c}\text { SC0126 } \\
\text { Retained Fuel }\end{array}$ & $\begin{array}{c}\text { Particle Size Range } \\
(\mu \mathrm{m})\end{array}$ & $\begin{array}{c}\text { SC0126 } \\
\text { Retained Fuel }^{\mathrm{a}}\end{array}$ \\
\hline$>5600$ & 0.8533 & $>9-10$ & 0.0000 \\
$>2000-5600$ & 0.0983 & $>8-9$ & 0.0000 \\
$>850-2000$ & 0.0354 & $>7-8$ & 0.0000 \\
$>425-850$ & 0.0072 & $>6-7$ & 0.0000 \\
$>180-425$ & 0.0031 & $>5-6$ & 0.0000 \\
$>125-180$ & 0.0010 & $>4-5$ & 0.0001 \\
$>45-75$ & 0.0005 & $>3-4$ & 0.0002 \\
$>30-45$ & 0.0000 & $>2-3$ & 0.0000 \\
$>20-30$ & 0.0001 & $>1-2$ & 0.0000 \\
$>10-20$ & 0.0002 & $<1$ & 0.0000 \\
\hline Total: & 1.0000 & & \\
Weight fraction $<10 \mu \mathrm{m}:$ & 0.0003 & & \\
a Approximately $0.0890 \mathrm{~g}$ fuel released. & \\
\hline \hline
\end{tabular}


Metallographic examination of the $\mathrm{Al} / \mathrm{Ir}$ reaction product revealed that it was clearly defined and homogeneous (Figure 21). The Al/Ir intermetallic compound contained several fractures. One of the intermetallic metallographic sections was submitted for scanning electron microscope (SEM) examination. The examination confirmed the presence of an $\mathrm{Al} / \mathrm{Ir}$ reaction product having an Al:Ir atomic ratio of approximately 7:3.

Examination of the two transverse shield cup breaches revealed intergranular failures with moderate grain elongation before failure (Figures 22 and 23). There was a minute deposit of the $\mathrm{A} 1 / \mathrm{Ir}$ intermetallic product at both fracture sites, but there were no indications that the formation of the intermetallic had contributed to the failures. Metallographic examination of the clad's discolored area revealed no unusual microstructure.

\section{DISCUSSION}

\section{A. Impact Response and Fuel Release}

The aluminum plate penetrated the converter housing, resulting in significant damage to the shell. The plate penetrated the target GPHS module, the leading-edge GIS, and the capsule at the open end of the GIS. This capsule, SC0126, was the only one of the four loaded ones that breached. The clad failures appeared to be the direct result of impact of the aluminum plate along a small area of the GPHS clad.
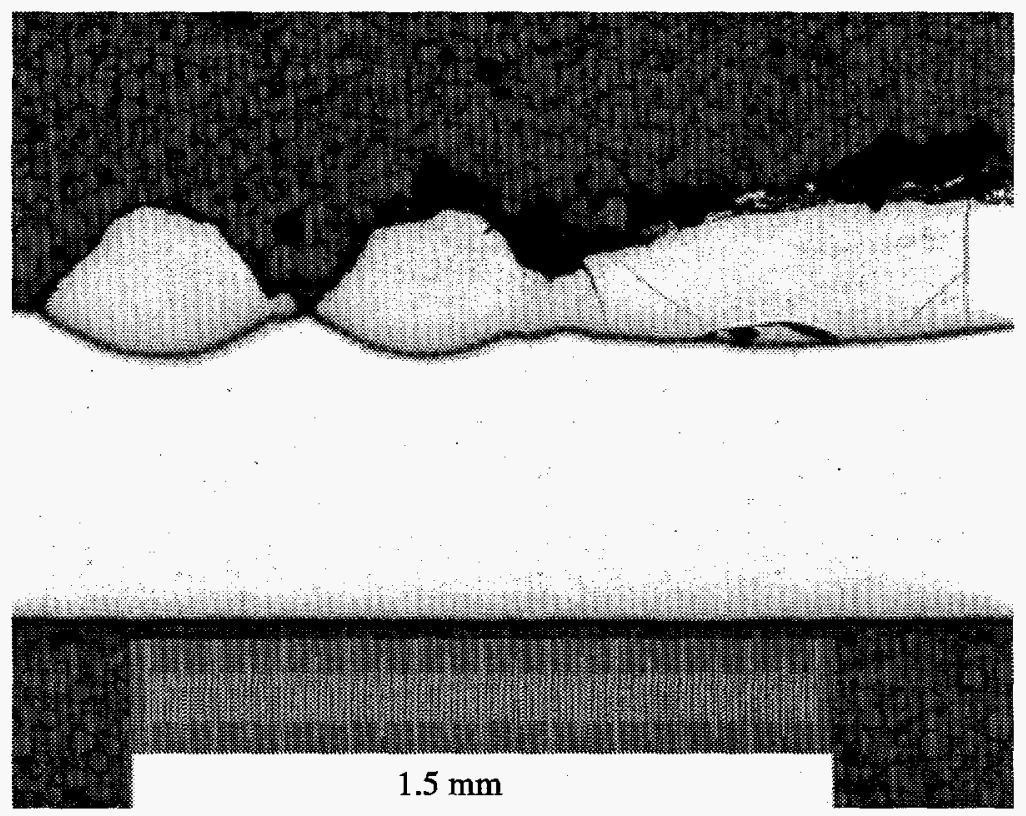

Figure 21. Typical microstructure of the Al/r intermetallic deposits. (Neg SC126-2-5) 


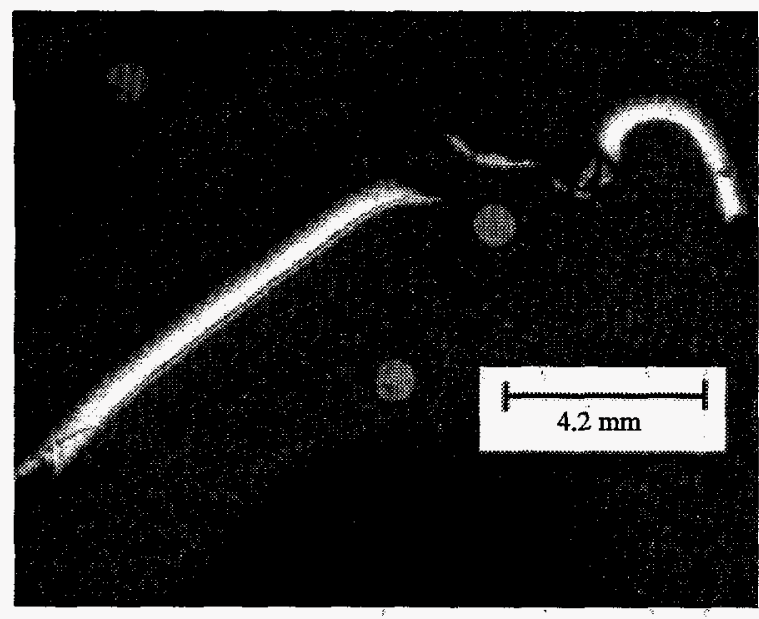

(a)

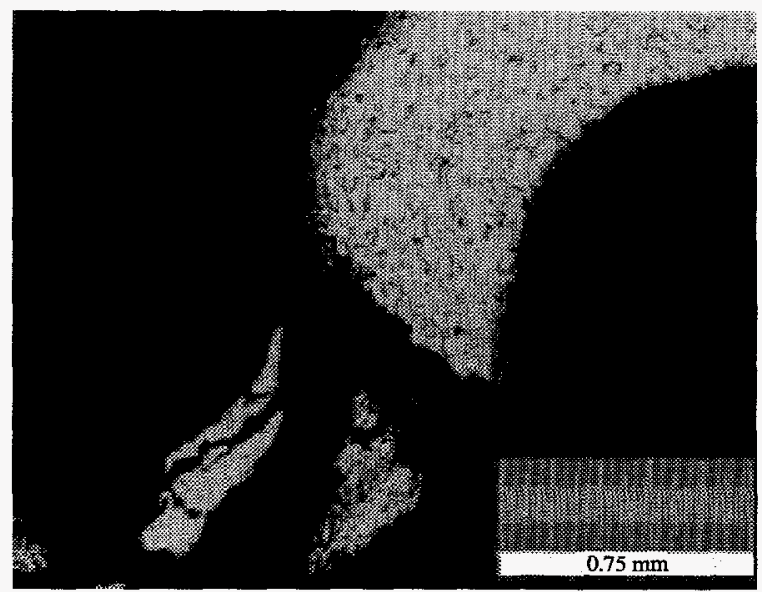

(c)

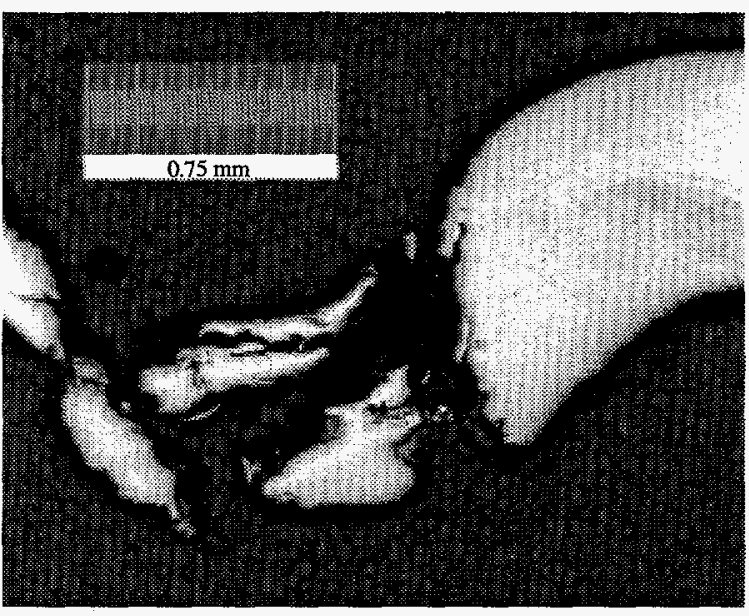

(b)

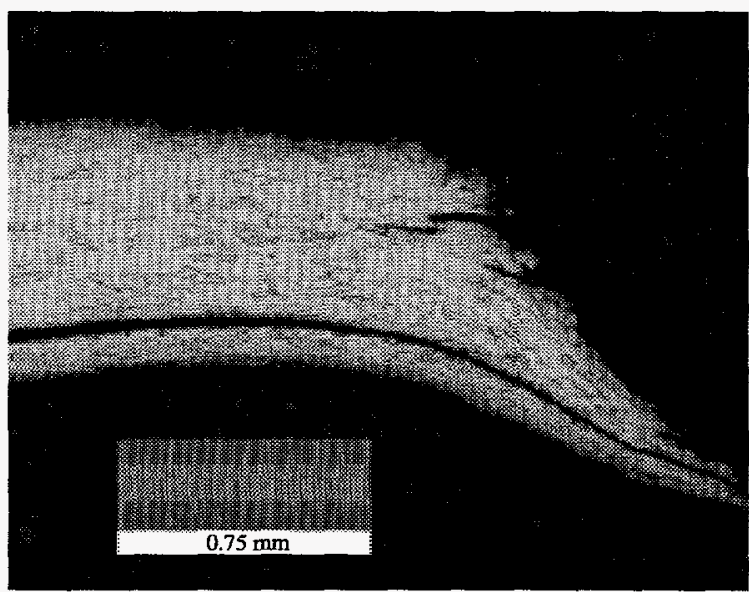

(d)

Figure 22. Transverse breaching crack: (a) metallographic sample; (b) polished fracture end with an Al/Ir intermetallic deposit; (c) fracture end, etched; and (d) the other fracture end, etched. (Negs SC126-8-1, $S C 126-8-3, S C 126-8-4$, and SC126-8-8).

There did not appear to be any failures resulting from fuel fragment push-through. The strain values of the clads were relatively low and, based on recent impact test results, would not have been expected to result in clad failures. ${ }^{15-16}$

Although a brittle $\mathrm{Al} / \mathrm{Ir}$ intermetallic deposit was formed by reaction of the aluminum plate with the hot iridium clad metal, it did not appear to have significantly affected the clad impact response. It may, however, have prevented a more significant release of fuel from the capsule. The reaction product surrounded the breaches and effectively reduced the size of the breaching cracks. 


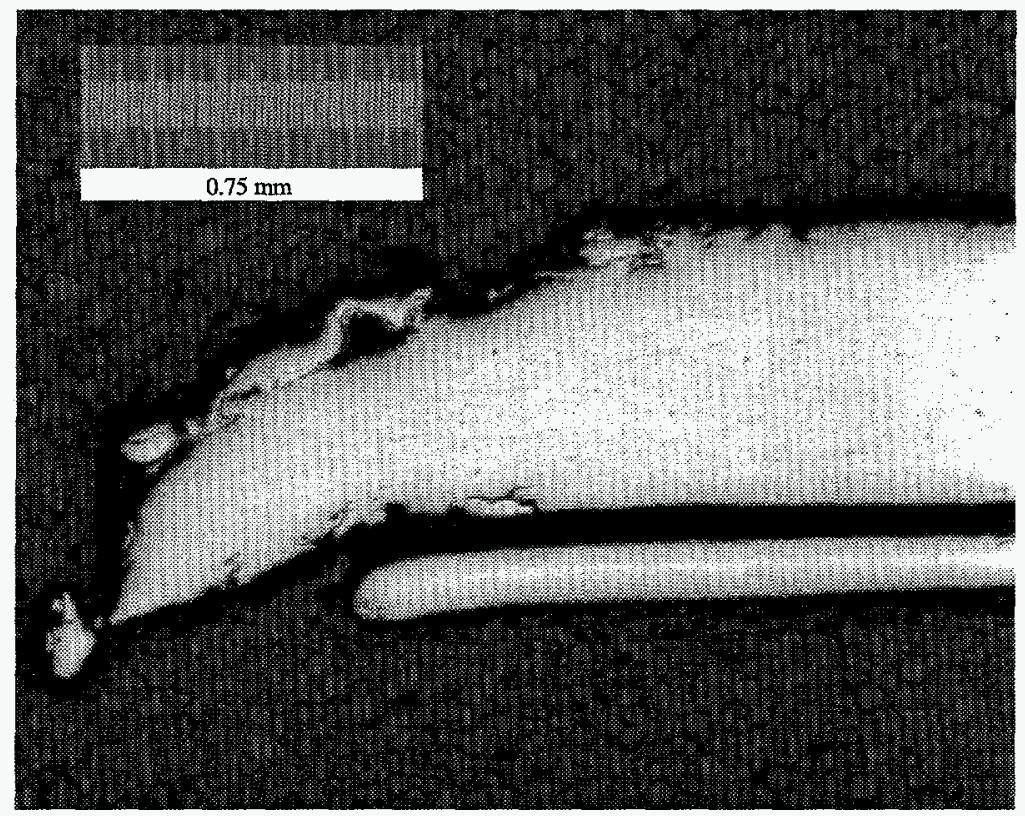

(a)

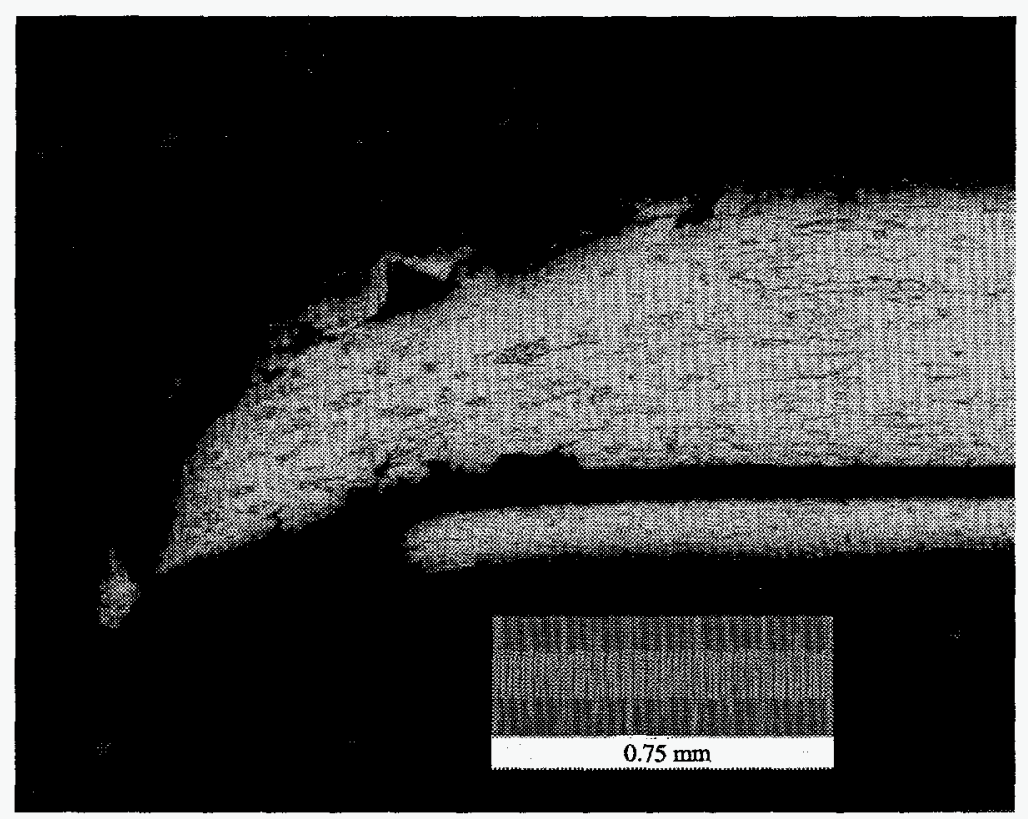

(b)

Figure 23. Transverse breaching crack, circle shaped: (a) polished fracture end with an Al/Ir intermetallic deposit and (b) fracture end, etched. (Negs SC126-7-2 and SCI26-7-3). 


\section{B. Pellet Fragmentation}

Table VII compares the particle-size distribution of urania recovered from other RTG impact tests and from SC0126. The distribution of SC0126 compares most closely with that of SC0107, recovered from RTG-2. The relative amount of SC0126 fuel in the $<100-\mu \mathrm{m}$ range is significantly less than in the other capsules. Capsule SC0107 was the least severely deformed of the breached capsules recovered from RTG-2. Capsule SC0126 was even less deformed than SC0107. However, it does appear that there may be a correlation between overall capsule deformation and fines generation, particularly for the $<10-\mu \mathrm{m}$ weight fraction.

TABLE VII. Pellet Fragmentation of Simulant-Fueled Clads in RTG Tests

\begin{tabular}{|c|c|c|c|c|c|}
\hline \multirow[b]{2}{*}{$\begin{array}{l}\text { Particle Size } \\
\text { Range }(\mu \mathrm{m})\end{array}$} & \multicolumn{5}{|c|}{ WEIGHT FRACTION, Retained Fuel } \\
\hline & $\begin{array}{c}\text { RTG-1 } \\
\text { SC0076 } \\
\end{array}$ & $\begin{array}{r}\text { RTG-2 } \\
\text { SC0092 } \\
\end{array}$ & $\begin{array}{c}\text { RTG-2 } \\
\text { SC0096 } \\
\end{array}$ & $\begin{array}{r}\text { RTG-2 } \\
\text { SC0107 } \\
\end{array}$ & SC0126 \\
\hline$>180$ & 0.9863 & 0.9834 & 0.9923 & 0.9974 & 0.9973 \\
\hline$>125-180$ & 0.0036 & 0.0027 & 0.0027 & 0.0004 & 0.0010 \\
\hline$>75-125$ & 0.0037 & 0.0025 & 0.0016 & 0.0004 & 0.0006 \\
\hline$>45-75$ & 0.0023 & 0.0027 & 0.0012 & 0.0008 & 0.0005 \\
\hline$>30-45$ & 0.0007 & 0.0012 & 0.0006 & 0.0002 & 0.0000 \\
\hline$>20-30$ & 0.0010 & 0.0020 & 0.0004 & 0.0002 & 0.0000 \\
\hline$>10-20$ & 0.0016 & 0.0035 & 0.0005 & 0.0003 & 0.0002 \\
\hline$\leq 10$ & 0.0008 & 0.0020 & 0.0007 & 0.0003 & 0.0003 \\
\hline Total: & 1.0000 & 1.0000 & 1.0000 & 1.0000 & 1.0000 \\
\hline
\end{tabular}

\section{CONCLUSIONS}

1. The side-on impact of a simulant RTG converter assembly with a thin aluminum fragment traveling at $306 \mathrm{~m} / \mathrm{s}$ resulted in significant damage to the converter and a small breach in one GPHS capsule.

2. The single GPHS capsule failure appeared to have been caused by penetration of the iridium clad by the thin aluminum plate.

3. The Al/Ir intermetallic produced by the reaction of the aluminum plate with the hot iridium cladding did not appear to have adversely affected the clad impact response and may have prevented a more significant release of fuel from the capsule.

4. The side-on plate impact resulted in minimal fuel fragmentation. 


\section{ACKNOWLEGMENTS}

We thank A. Herrera, M. Barney, and D. Montoya for designing and conducting the field tests and E. Burciaga, C. Lynch, and P. Moniz for performing metallography, sample preparation, and particle-size analyses. We would like to give special thanks to B. Kampfe and F. Mathews of Sandia National Laboratories for design of the sleds and coordination of tests at the Sandia sled test facility.

\section{REFERENCES}

1. C. T. Bradshaw, "Safety Test Program Plan for the Cassini RTG Program," Martin Marietta Astro Space report CDRL No. A. 10, GESP-7223 (May 1993).

2. F. W. Schonfeld, "General-Purpose Heat Source Development: Safety Test Program, Postimpact Evaluation, Design Iteration Test 1," Los Alamos National Laboratory report LA-9680-SR (April 1984).

3. F. W. Schonfeld and T. G. George, "General-Purpose Heat Source Development: Safety Test Program, Postimpact Evaluation, Design Iteration Test 2," Los Alamos National Laboratory report LA-10012-SR (June 1984).

4 F. W. Schonfeld and T. G. George, "General-Purpose Heat Source Development: Safety Test Program, Postimpact Evaluation, Design Iteration Test 3," Los Alamos National Laboratory report LA-10034-SR (July 1984).

5. T. G. George and F. W. Schonfeld, "General-Purpose Heat Source Development: Safety Test Program, Postimpact Evaluation, Design Iteration Test 4," Los Alamos National Laboratory report LA-10217-SR (December 1984).

6. T. G. George and F. W. Schonfeld, "General-Purpose Heat Source Development: Safety Test Program, Postimpact Evaluation, Design Iteration Test 5," Los Alamos National Laboratory report LA-10232-SR (December 1984).

7. D. Pavone, T. G. George, and C. E. Frantz, "General-Purpose Heat Source Safety Verification Test Series: SVT-1 through SVT-6," Los Alamos National Laboratory report LA-10353-MS (June 1985).

8. T. G. George and D. Pavone, "General-Purpose Heat Source Safety Verification Test Series: SVT-7 through SVT-10," Los Alamos National Laboratory report LA-10408MS (September 1985). 
9. T. G. George and D. Pavone, "General-Purpose Heat Source Safety Verification Test Series: SVT-11 through SVT-13," Los Alamos National Laboratory report LA-10710MS (May 1986).

10. T. G. George, R. E. Tate, and K. M. Axler, "General-Purpose Heat Source Development: Safety Verification Test Program, Bullet/Fragment Test Series," Los Alamos National Laboratory report LA-10364-MS (May 1985).

11. T. G. George, "General-Purpose Heat Source Development: Safety Verification Test Program, Titanium Bullet/Fragment Test Series," Los Alamos National Laboratory report LA-10724-MS (June 1986).

12. T. A. Cull, T. G. George, and D. Pavone, "General-Purpose Heat Source Development: Safety Verification Test Program, Explosion Overpressure Test Series," Los Alamos National Laboratory report LA-10697-MS (September 1986).

13. T. A. Cull and D. Pavone, "General-Purpose Heat Source Development: Safety Verification Test Program, Flyer Plate Test Series," Los Alamos National Laboratory report LA-10742-MS (September 1986).

14. T. G. George, "General-Purpose Heat Source Development: Safety Verification Test Program, Edge-On Flyer Plate Tests," Los Alamos National Laboratory report LA-10872-MS (March 1987).

15. M. A. H. Reimus, J. E. Hinckley, and T. G. George, "General-Purpose Heat Source: Research and Development Program, Radioisotope Thermoelectric Generator Impact Tests: RTG-1 and RTG-2,' Los Alamos National Laboratory report LA-13147 (July 1996)

16. M. A. H. Reimus and T. G. George, "General-Purpose Heat Source: Research and Development Program, Cold-Process Verification Test Series," Los Alamos National Laboratory report LA-13118 (June 1996). 